\title{
Cold-inducible RNA-binding protein through TLR4 signaling induces mitochondrial DNA fragmentation and regulates macrophage cell death after trauma
}

\author{
Zhigang Li ${ }^{1,2}$, Erica K Fan ${ }^{3}$, Jinghua Liu ${ }^{4}$, Melanie J Scott ${ }^{1}$, Yuehua $\mathrm{Li}^{1,2}$, Song $\mathrm{Li}^{5}$, Wen $\mathrm{Xie}^{5}$, Timothy R Billiar ${ }^{1,6}$, Mark A Wilson ${ }^{1,2}$, \\ Yong Jiang ${ }^{4}$, Ping Wang ${ }^{7}$ and Jie Fan ${ }^{\star 1,2,6}$
}

Trauma is a major cause of systemic inflammatory response syndrome and multiple organ dysfunction syndrome. Macrophages $(\mathrm{M} \phi)$ direct trauma-induced inflammation, and $\mathrm{M} \phi$ death critically influences the progression of the inflammatory response. In the current study, we explored an important role of trauma in inducing mitochondrial DNA ( $m$ tDNA) damage in M $\phi$ and the subsequent regulation of $\mathrm{M} \phi$ death. Using an animal pseudo-fracture trauma model, we demonstrated that tissue damage induced NADPH oxidase activation and increased the release of reactive oxygen species via cold-inducible RNA-binding protein (CIRP)-TLR4MyD88 signaling. This in turn, activates endonuclease G, which serves as an executor for the fragmentation of mtDNA in M $\phi$. We further showed that fragmented mtDNA triggered both p62-related autophagy and necroptosis in $M \phi$. However, autophagy activation also suppressed $\mathbf{M} \phi$ necroptosis and pro-inflammatory responses. This study demonstrates a previously unidentified intracellular regulation of $\mathrm{M} \phi$ homeostasis in response to trauma.

Cell Death and Disease (2017) 8, e2775; doi:10.1038/cddis.2017.187; published online 11 May 2017

Traumatic injury represents a significant health care burden worldwide. ${ }^{1}$ Initial mortality is usually secondary to major neurologic injury or massive hemorrhage..$^{2,3}$ For those victims of severe traumatic injury who survive beyond the initial $24 \mathrm{~h}$, major morbidities and mortality are often secondary to immune dysregulation, which includes increased inflammatory and innate immune signaling, as well as suppression of adaptive immune signaling. The net result leads to organ dysfunction and increased susceptibility to infection with the development of sepsis. ${ }^{4-7}$ Unfortunately, we do not have effective medical intervention for these trauma patients, partly because of an incomplete understanding of the cellular determinants of immune dysregulation following trauma.

Macrophages $(\mathrm{M} \phi)$, as a major innate immune cell population, direct trauma-induced inflammation, and $\mathrm{M} \phi$ death critically influences the progression of inflammatory responses. M $\phi$ necroptosis has been reported as a response to infection, as well as sterile inflammatory stimuli such as LPS. $^{8-11}$ In turn, necroptotic M $\phi$ enhance inflammation through release of pro-inflammatory cell contents. ${ }^{12}$

Cold-inducible RNA-binding protein (CIRP) is a member of the cold shock protein family. ${ }^{13}$ Mouse and human CIRP contain 172 amino-acid residues (95\% identical) that form a consensus sequence of $\mathrm{N}$-terminal RAN-binding domain and C-terminal glycine-rich domain of nuclear proteins, which serve as RNA chaperones promoting RNA translation. ${ }^{14,15}$ $\mathrm{CIRP}$ has been defined as an inflammatory mediator and a damage-associated molecular pattern (DAMP), which highly expresses during trauma and shock, ${ }^{16,17}$ and induces a variety of cellular responses including the release of proinflammatory cytokines and endothelial dysfunction. ${ }^{18}$

In addition to supplying cellular energy, mitochondria are also involved with other functions including signal transduction, cell differentiation and death, and the maintenance of the cell cycle and cell growth control processes. ${ }^{19}$ In mammals, mitochondrial DNA (mtDNA) is circular with 15-17 000 base pairs encoding 37 genes, including 13 genes for respiratory complexes I, III, IV, and V. ${ }^{20,21}$ Extracellular mtDNA is a known DAMP mediating inflammatory responses through a TLR9 signaling pathway during sepsis. ${ }^{22,23}$ However, the role of intracellular-damaged mtDNA in the regulation of cellular homeostasis of innate immune cells has yet to be addressed.

Endonuclease $\mathrm{G}$ is an apoptotic DNase, located in the mitochondrial intermembrane space. ${ }^{24}$ The precursor of endonuclease $\mathrm{G}$ is an inactive $33 \mathrm{kDa}$ protein, which must be activated by proteolytic cleavage to a $28 \mathrm{kDa}$ form. ${ }^{25}$ Degradation of DNA by endonuclease $G$ is independent of caspases. ${ }^{26}$ During animal development endonuclease $\mathrm{G}$ also functions to degrade mtDNA. ${ }^{27}$

In this study, we explored an important role for trauma in inducing mtDNA damage in $M \phi$, but not in neutrophils, and subsequently regulating $M \phi$ death. Using an animal pseudofracture (PF) trauma model, ${ }^{28}$ we demonstrate that tissue damage acts through CIRP-TLR4-MyD88 signaling to induce

\footnotetext{
${ }^{1}$ Department of Surgery, University of Pittsburgh School of Medicine, Pittsburgh, PA 15213, USA; ${ }^{2}$ Research and Development, Veterans Affairs Pittsburgh Healthcare System, Pittsburgh, PA 15240, USA; ${ }^{3}$ University of Pittsburgh School of Arts and Science, Pittsburgh, PA 15213, USA; ${ }^{4}$ Guangdong Provincial Key Laboratory of Proteomics, State Key Laboratory of Organ Failure Research, Southern Medical University, Guangzhou 510515, China; ${ }^{5}$ Department of Pharmaceutical Sciences, Center for Pharmacogenetics, University of Pittsburgh School of Pharmacy, Pittsburgh, PA 15261, USA; ${ }^{6}$ McGowan Institute for Regenerative Medicine, University of Pittsburgh, Pittsburgh, PA 15219, USA and ${ }^{7}$ The Feinstein Institute for Medical Research, Manhasset, NY 11030, USA

*Corresponding author: J Fan, Department of Surgery, University of Pittsburgh School of Medicine, Building 1, 1W142 (151U), University Drive, VAPHS, Pittsburgh, PA 15240, USA. Tel: +412 360 6204; Fax: +412 360 6633; E-mail: jif7@ pitt.edu

Received 16.1.17; revised 24.3.17; accepted 27.3.17; Edited by B Zhivotovsky
} 
NADPH oxidase activation, which increases release of reactive oxygen species (ROS) and activates endonuclease $\mathrm{G}$. Endonuclease $\mathrm{G}$ serves as an executor to fragment mtDNA in the $\mathrm{M} \phi$, which we further demonstrate triggers both p62-related autophagy and necroptosis in $\mathrm{M} \phi$, although autophagy activation suppressed $M \phi$ necroptosis and

a
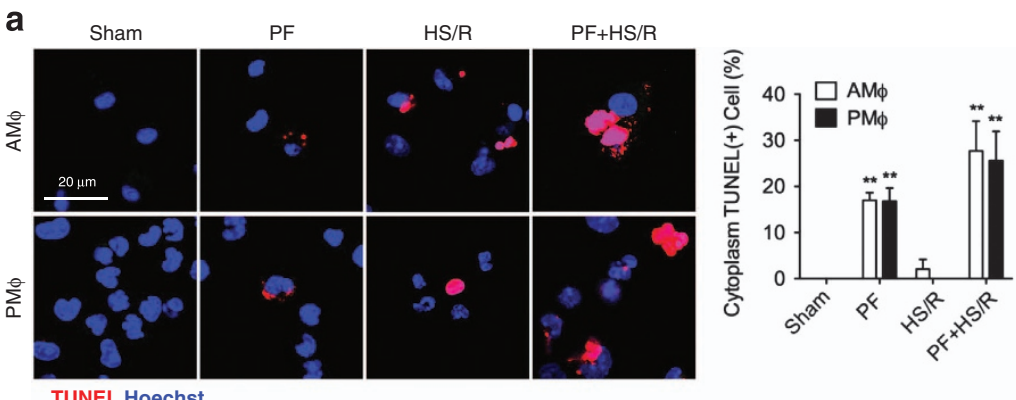

TUNEL Hoechs

b
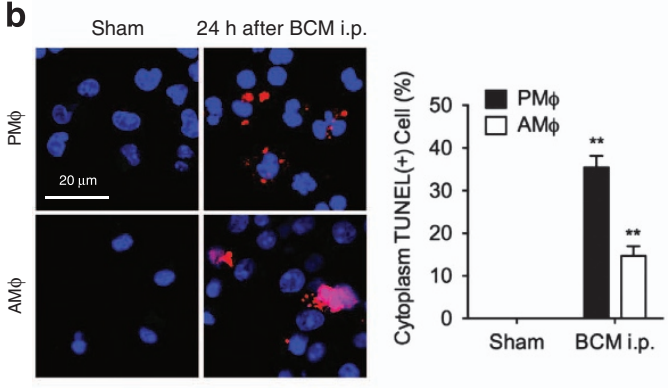

TUNEL Hoechst

C
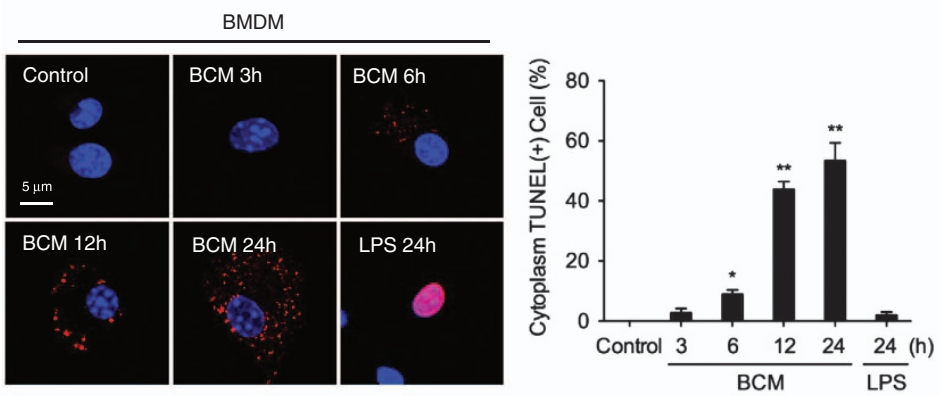

TUNEL Hoechst

d $\quad \mathrm{J} 774.2$
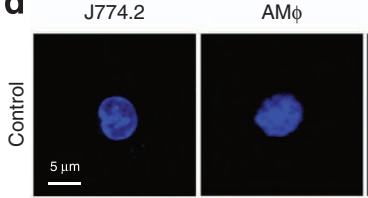

$\mathrm{PM} \phi$
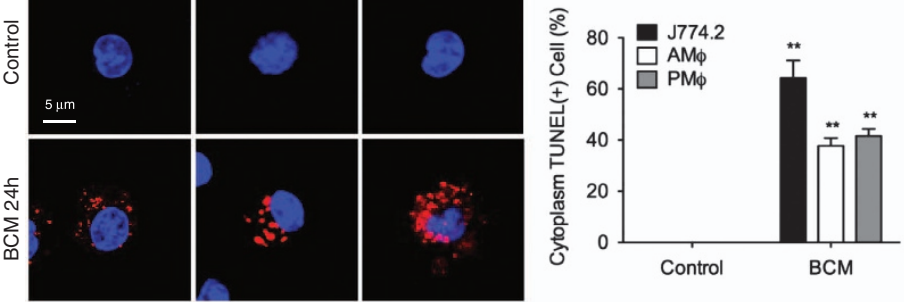

TUNEL Hoechs

e
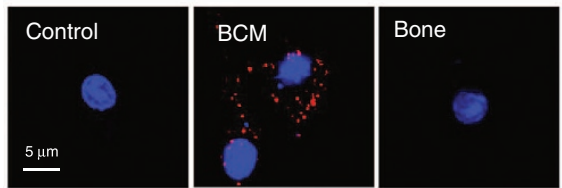

TUNEL Hoechst

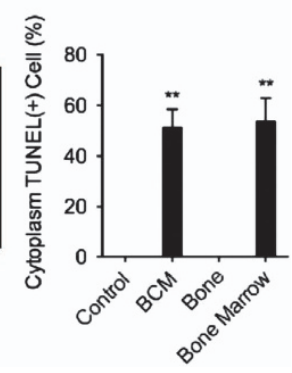


pro-inflammatory responses. Our study therefore demonstrates a previously unidentified intracellular regulation pathway of $\mathrm{M} \phi$ homeostasis in response to trauma.

\section{Results}

PF induces macrophage cytoplasmic DNA fragmentation. To determine M $\phi$ DNA damage in response to trauma, WT mice were subjected to $\mathrm{PF}^{28}$ a trauma model mimicking long bone fracture, or to hemorrhagic shock with resuscitation (HS/ $\mathrm{R}$ ), or to both PF and HS/R double hit. We used the TUNEL assay to detect DNA fragmentation as a marker of DNA damage. In the PF model, both alveolar macrophages (AM $\phi)$ and peritoneal macrophages (PM $\phi)$ exhibited TUNEL-positive dots in cytoplasm (Figure 1a). However, TUNEL staining colocalized with Hoechst stain (nuclear DNA) in HS/R model (Figure 1a). Furthermore, in mice subjected to the PF and HS/ $R$ double hit TUNEL staining localized to both the nucleus and cytoplasm (Figure 1a). These results suggest that HS/R and PF induce DNA fragmentation in M $\phi$ differently. To determine whether mediators in the bone crush mixture (BCM) used in the PF model contribute to the effect of PF on M $\phi$ cytoplasmic DNA fragmentation, BCM $(6 \mathrm{ml} / \mathrm{kg}$ B.W.) was directly injected into the mouse peritoneal cavity. $\mathrm{PM} \phi$ and $\mathrm{AM} \phi$ were harvested at $24 \mathrm{~h}$ and DNA damage measured by TUNEL assay as above. As shown in Figure 1b, PM $\phi$ cytoplasmic DNA fragmentation significantly increased. Interestingly, BCM i.p. injection also $\phi$-induced cytoplasmic DNA fragmentation in $A M \phi$. This result suggests that BCM can induce cytoplasmic DNA fragmentation in both proximal and distal Mø.

The in vivo study was also recapitulated in vitro. Bone marrow-derived macrophage (BMDM) were treated with BCM $(40 \mu \mathrm{l} / \mathrm{ml})$ for $24 \mathrm{~h}$, and as shown in Figure 1c, the percentage of $M \phi$ with TUNEL-positive cytoplasm increased significantly by $6 \mathrm{~h}$ after BCM treatment, and peaked at $24 \mathrm{~h}$. However, LPS-induced DNA fragmentation was localized to the nucleus, which was different from BCM-induced cytoplasmic DNA fragmentation (Figure 1c). We also directly treated different $\mathrm{M} \varpi$ with BCM in vitro. As shown in Figure 1d, BCM-induced cytoplasmic DNA fragmentation in $\mathrm{J} 774.2$ mouse monocyte cell line, and $\mathrm{AM} \varpi$, and $\mathrm{PM} \phi$. We further separated the BCM into two parts, bone and bone marrow, and found that only the bone marrow was able to induce $M \phi$ cytoplasmic DNA fragmentation (Figure 1e). Collectively, these results suggest that PF induces M $\phi$ cytoplasmic DNA fragmentation and it is bone marrow components of the $\mathrm{BCM}$ that are responsible for these effects.
Damaged tissue induces macrophage mtDNA fragmentation. In order to determine the source of fragmented DNA and exclude exogenous DNA, BCM was pretreated with nuclease to remove DNA/RNA. As shown in Figure $2 \mathrm{a}$, nuclease successfully cleared DNA from BCM. However, nuclease-pretreated BCM was still able to induce BMDM cytoplasmic TUNEL dots similarly to non-pretreated groups (Figure 2b). M $\phi$ endocytosis of exogenous DNA is commonly localized to endosome, ${ }^{29}$ so we therefore detected colocalization of fragmented DNA with endosomes that were visualized by staining early endosome antigen 1 (EEA1), which localizes early endosomes and is required for fusion of early and late endosomes. As Figure 2c shows, the fragmented DNA does not localize to endosomes, suggesting an endogenous source of fragmented DNA. Next, we determined whether endogenous fragmented DNA derived from mitochondria. Confocal microscopy showed that BCMinduced fragmented DNA partly colocalized with mitochondria, as stained by Mitotracker, and partly localized to areas surrounding mitochondria suggesting mitochondrial origin (Figure 2d). Both BCM and nuclease-pretreated BCM also increased levels of mtDNA by $6 \mathrm{~h}$ (Figure 2e), but this increase was reversed by $24 \mathrm{~h}$ (Figure $2 \mathrm{f}$ ). To calculate the mtDNA damage rate, as shown in Figure $2 \mathrm{~g}, \mathrm{BCM}$ induces about $5 \%$ of total mtDNA damage at $6 \mathrm{~h}$ and about $15 \%$ mtDNA damage at $24 \mathrm{~h}$.

BCM is essentially a damaged tissue containing multiple DAMPs including the major DAMPs CIRP and HMGB1 as detected with immunoblots (Figure $2 h$ ). To address which of these two DAMPs is the major component inducing macrophage mtDNA fragmentation, we stimulated BMDM with recombinant CIRP or HMGB1. Recombinant CIRP induced TUNEL-positive BMDM cytoplasm similarly to BCM, but recombinant HMGB1 did not have the same effects (Figure 2i). CIRP (10 $\mu \mathrm{g} / \mathrm{ml})$, rather than recombinant HMGB1, significantly induced increased levels of mtDNA by $6 \mathrm{~h}$. (Figure 2j). Furthermore, while CIRP-induced mtDNA damage increased, CIRP neutralizing antibody reduced the BCMinduced mtDNA damage as compared to the group treated with nonspecific IgG isotype antibody (Figure $2 k$ ). The recombinant HMGB1, again, did not induce the mtDNA damage (Figure 2k).

To further define the role of the mtDNA responses to $B C M$, we generated mtDNA-depleted M $\phi$. Previous studies showed that treatment of $\mathrm{J} 774.2 \mathrm{M} \phi$ with ethidium bromide $(\mathrm{EtBr})$ for 7-14 days effectively depletes mtDNA. ${ }^{30-32}$ We confirmed mtDNA levels in the $\mathrm{J} 774.2$ cells decreased to $\sim 10 \%$ after $100 \mathrm{ng} / \mathrm{ml}$ of EtBr treatment for 7-14 days using three different

Figure 1 Pseudofracture induces macrophage cytoplasmic DNA fragmentation. (a) Alveolar macrophages (AM $\phi)$ and peritoneal macrophages (PM $\phi)$ from WT mice divided into one of the following: (1) sham for $24 \mathrm{~h}$; (2) pseudofracture (PF) for $24 \mathrm{~h}$; (3) hemorrhagic shock with resuscitation (HS/R) for $24 \mathrm{~h}$; (4) PF with HS/R (PF+HS/R) for $24 \mathrm{~h}$, and staining with TUNEL and Hoechst. Staining visualized by confocal microscopy and quantified. Cells were counted in three random fields for each independent experiment. (b) $\mathrm{AM} \phi$ and $\mathrm{PM} \phi$ from WT mice subjected to bone crush mixture (BCM; $6 \mathrm{ml} / \mathrm{kg}$ B.W. i.p.) for $24 \mathrm{~h}$, and then stained with TUNEL and Hoechst, and visualized by confocal microscopy and quantified. (c) TUNEL and Hoechst staining in BMDM treated with $40 \mu / / \mathrm{ml}$ of BCM for 0-24 h, or treated with $1 \mu \mathrm{g} / \mathrm{ml}$ LPS for $24 \mathrm{~h}$. (d) TUNEL and Hoechst staining in J774.2 monocyte/M $\phi$ cell line, AM $\phi$ and PM $\phi$ treated with $40 \mu \mathrm{l} / \mathrm{ml}$ of BCM for $24 \mathrm{~h}$. Immunofluorescence imaged by confocal microscopy and quantified. (e) TUNEL and Hoeschst staining in BMDM treated with BCM, bone or bone marrow isolated from femurtibia or WT mouse for $24 \mathrm{~h}$. Confocal microscopy images also quantified. All results are representative of three independent experiments. The graphs show the mean and S.E.M., $n=3$. Significances between groups were determined by using independent samples two-tailed Student's $t$-test. ${ }^{*} P<0.05$ or ${ }^{* *} P<0.01$ compared with sham or control groups 
pairs of mtDNA primers (see Materials and Methods), which produced consistent results showing mtDNA depletion (Figure 2I). In depleted cells, BCM failed to induce the large increase in mtDNA seen in Figure $2 \mathrm{~m}$. When visualized, levels of fragmented mtDNA at $24 \mathrm{~h}$ after BCM treatment decreased in $\mathrm{EtBr}$ pretreated $\mathrm{J} 774.2$ cells (Figure $2 \mathrm{n}$ ). These results indicate that damaged tissue induces $M \phi$ mtDNA fragmentation, and CIRP, but not HMGB1, serves as a DAMP molecule inducing these changes.
$B C M$-induced mtDNA fragmentation is mediated through TLR4-MyD88 signaling. CIRP has been reported to signal via TLR4-MyD88 signaling pathways to promote inflammation. ${ }^{17,33}$ To address whether PF, through TLR4MyD88 signaling, induces mtDNA fragmentation, we used $\mathrm{TLR}^{-1-}, \mathrm{MyD}^{-1-}, \mathrm{TLR}^{-1-}$, and $\mathrm{TLR}^{-1-}$ mice. As shown in Figure 3a, PF-induced mtDNA fragmentation is

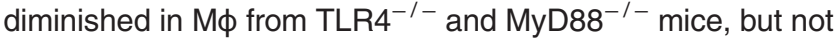
in $\mathrm{M} \phi$ from $\mathrm{TLR}^{-/-}$and $\mathrm{TLR}^{-/-}$mice. Similar results were a

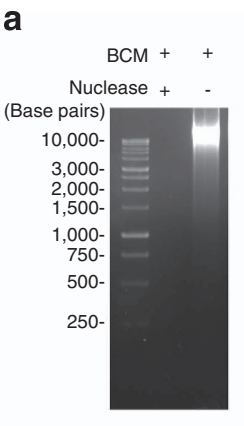

b

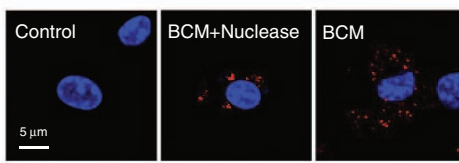

TUNEL Hoechst

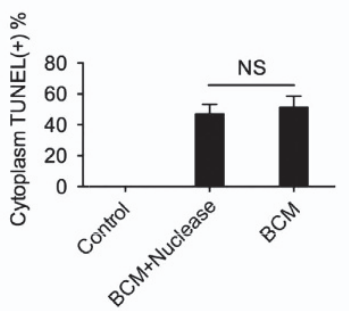

C

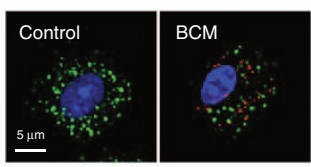

EEA1 TUNEL Hoechst

d

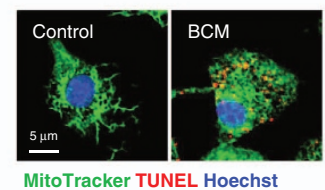

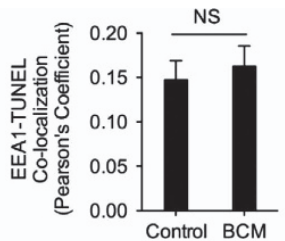

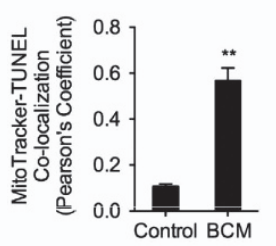

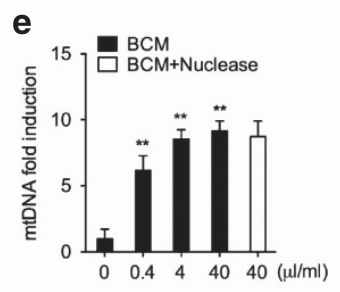
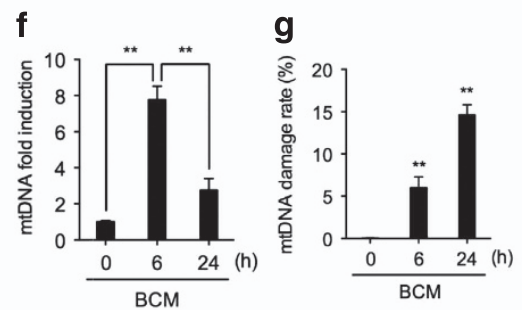

i
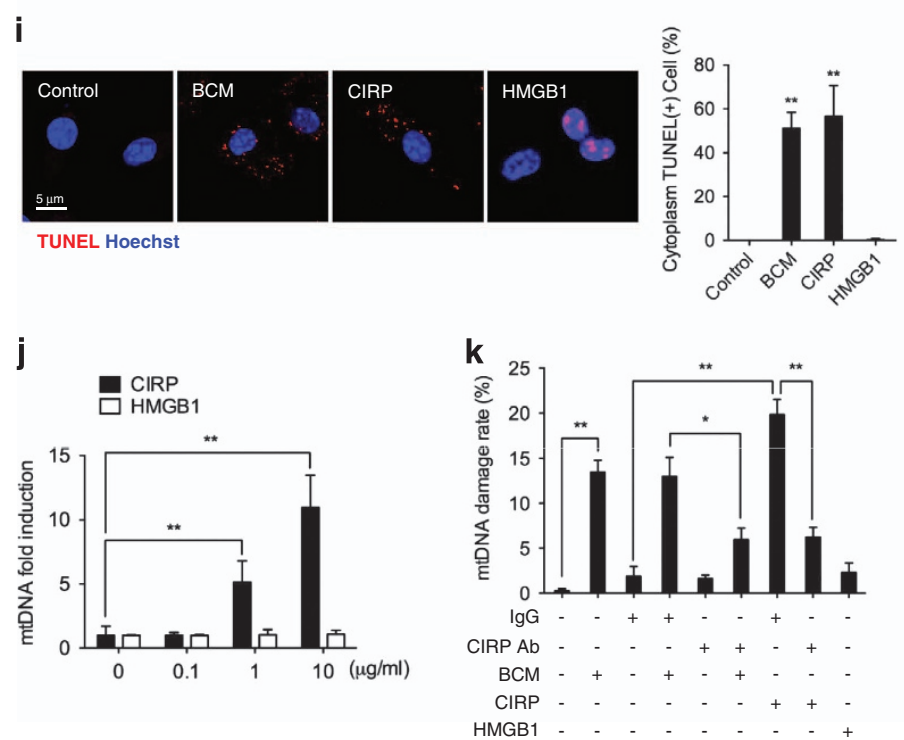

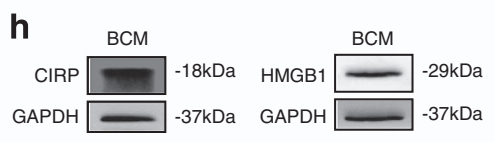

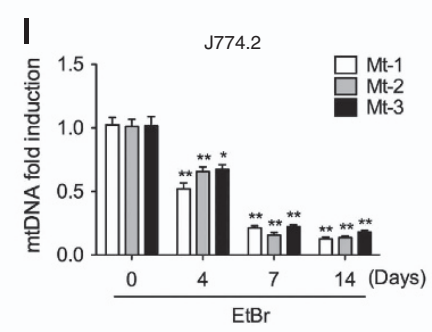

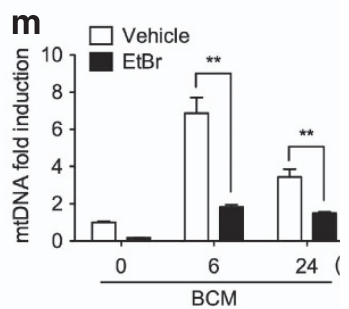

n
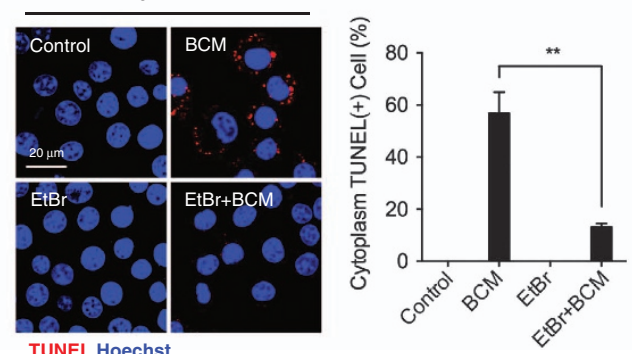
also observed in vitro, with significantly decreased cytoplas-

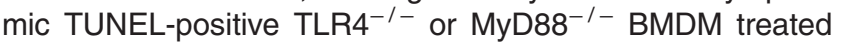
with BCM or CIRP (Figure 3b). Consistently, BCM- or CIRPinduced mtDNA levels at $6 \mathrm{~h}$ (Figure 3c) and mtDNA damage at $24 \mathrm{~h}$ (Figure $3 \mathrm{~d}$ ) were significantly diminished in $\mathrm{TLR}^{-1-}$ and $\mathrm{MyD}^{-1-} \mathrm{BMDM}$. These results suggest that BCM and its component CIRP act through the TLR4-MyD88 signaling pathway to induce mtDNA fragmentation.

ROS mediates mtDNA fragmentation. Previous studies showed that oxidative stress induces mitochondrial dysfunction and mtDNA damages. ${ }^{34,35}$ The NADPH oxidases from NOX family act as a key ROS producers in various cells. ${ }^{36,37}$ To address whether NADPH oxidase-derived ROS mediate BCM-induced mtDNA damage, we subjected WT or gp91 $1^{\text {phox-l- }}$ BMDM to challenge with BCM for 0-24 h. Gp91 $1^{\text {phox }}$ is one of the five subunits of NADPH oxidase, and gp91 ${ }^{\text {phox }-1-}$ cells do not have NADPH oxidase activity. ${ }^{38}$ As shown in Figure 4a, BCM induced WT BMDM ROS increase after $6 \mathrm{~h}$, as measured by CM-H2DCFDA, a general oxidative stress indicator, while the $\mathrm{gp} 91^{\text {phox }-1-}$ prevented $\mathrm{BCM}$-induced intracellular ROS increase. This suggests that NADPH oxidase is one of the important ROS sources induced by BCM. In addition, CIRP neutralizing antibody significantly decreased the BCM-induced ROS production in WT BMDM (Figure 4b). Furthermore, recombinant CIRP induced ROS increase in WT BMDM, while this was significantly decreased in gp91 $1^{\text {phox }-/-}$ BMDM given CIRP for up to $24 \mathrm{~h}$ (Figure 4c). We also measured NADPH oxidase activation in BMDM, by measuring $\mathrm{p} 47^{\text {phox }}$ phosphorylation and $\mathrm{p} 47^{\text {phox }}$ association with gp9 $1^{\text {phox }}$ by immunoprecipitation (IP). As shown in Figures 4d and e, BCM induced p47 $7^{\text {phox }}$ phosphorylation in WT BMDM at as early as $1 \mathrm{~h}$, and the association of $\mathrm{p} 47^{\text {phox }}$ with $\mathrm{gp} 91^{\text {phox }}$ increased by $4 \mathrm{~h}$ after BCM treatment. Furthermore, gp91 $1^{\text {phox-l- }}$ BMDM had significantly reduced levels of TUNEL-positive cytoplasm after stimulation with either BCM or CIRP (Figure 4f). BMDM from gp91 ${ }^{\text {phox }-1-}$ mice had reduced levels of mtDNA compared with WT BMDM (Figure $4 \mathrm{~g}$ ) and reduced levels of mtDNA damage after BCM or CIRP treatment (Figure 4h). These results clearly indicate that NADPH oxidase-derived ROS play an important role in the mechanism underlying BCM-induced mtDNA damage.
Endonuclease $G$ fragments mtDNA in $M \phi$ after BCM treatment. Previous studies reported that endonuclease $\mathrm{G}$, which locates at mitochondrial inner membrane, fragments chromosomal DNA in caspase-independent apoptosis. ${ }^{26}$ Furthermore, the endonuclease $\mathrm{G}$ also degrades mtDNA during animal development. ${ }^{27,39}$ To determine the role of endonuclease $G$ in mtDNA fragmentation in $M \phi$, we measured changes in endonuclease $G$ protein and mRNA levels after BCM stimulation. As shown in Figure $5 \mathrm{a}$, BCM increased protein expression of mature endonuclease $G$ (28 kDa) by $12 \mathrm{~h}$ after BCM stimulation. Interestingly, endonuclease G mRNA level was not significantly changed (Figure 5b). CIRP recombinant protein increased mature endonuclease $\mathrm{G}$ expression, while CIRP neutralizing antibody prevented the BCM- and CIRP-induced increase (Figure $5 \mathrm{c}$ ). We also determined the cellular location of endonuclease $\mathrm{G}$ in WT BMDM after BCM stimulation (Figure $5 d$ ) and show that it colocalizes with mitochondria both before and after BCM stimulation.

To determine whether the endonuclease $\mathrm{G}$ expression is dependent on NADPH oxidase, we compared protein levels of mature endonuclease G in WT and gp91 ${ }^{\text {phox-l- }}$ BMDM in response to $\mathrm{BCM}$ or CIRP. BMDM from gp91 ${ }^{\text {phox }-/-}$ mice challenged with BCM (Figure 5e) or CIRP (Figure 5f) exhibited markedly lower level of mature endonuclease $G$ expression compared to WT BMDM. Furthermore, we investigated the role of endonuclease $G$ in mtDNA fragmentation using endonuclease $\mathrm{G}$ knockdown approach. Transfection of small interfering RNA against endonuclease G (siEndoG) successfully knocked down endonuclease $\mathrm{G}$ in BMDM as shown by very low levels of endonuclease $G$ mRNA (Figure $5 \mathrm{~g}$ ). Transfection with siEndoG significantly decreased BCMinduced mtDNA damage (Figure 5h) and TUNEL-positive cytoplasmic staining (Figure $5 \mathrm{i}$ ) as compared with BMDM transfected with control non-coding siRNA (siNC). These data indicate that NADPH oxidase induces increased expression of mature endonuclease $\mathrm{G}$, which mediates BCM-induced mtDNA damage, therefore suggesting that endonuclease $G$ is the executor of mtDNA fragmentation.

Fragmented mtDNA induces $M \phi$ autophagy. Autophagy refers to a cell self-regulation process, allowing orderly degradation and recycling of abnormal cell components. ${ }^{40}$

Figure 2 Damaged tissue induces macrophage mtDNA fragmentation. (a) Separation of DNA fragments by agarose gel electrophoresis in BCM treated with or without nuclease. (b) Confocal images and quantification of TUNEL and Hoechst staining of BMDM treated for $24 \mathrm{~h}$ with nuclease pretreated or non-pretreated BCM (40 $\mu / / \mathrm{ml})$. (c) Immunofluorescence images showing the colocalization and quantification of colocalization of endosome (EEA1; green) and fragmented DNA (TUNEL; red) in BMDM treated with $40 \mu / \mathrm{ml} \mathrm{BCM}$ for $24 \mathrm{~h}$. (d) Confocal immunofluorescence images showing colocalization and quantification of colocalization of mitochondria (MitoTracker; green) and fragmented DNA (TUNEL; red) in BMDM treated with BCM $(40 \mu / / \mathrm{ml})$ for $24 \mathrm{~h}$. (e) Quantification of fold induction of mtDNA measured by RT-PCR in BMDM treated with 0-40 $\mu / / \mathrm{ml}$ BCM or $40 \mu / \mathrm{ml}$ nuclease-pretreated BCM for $6 \mathrm{~h}$. (f) mtDNA fold induction and (g) mtDNA damage measured by RT-PCR in BMDM treated with BCM (40 $\mu / / \mathrm{ml})$ for 0,6 , or $24 \mathrm{~h}$. (h) Western blot for CIRP and HMGB1 expression in BCM. (i) Confocal images and quantification of TUNEL and Hoechst staining of BMDM challenged with BCM (40 $\mu / / \mathrm{ml})$, CIRP $(10 \mu \mathrm{g} / \mathrm{ml})$, or HMGB1 $(10 \mu \mathrm{g} / \mathrm{ml})$ for $24 \mathrm{~h}$. (j) mtDNA fold induction measured by RT-PCR in BMDM treated with 0-10 $\mu \mathrm{g} / \mathrm{ml}$ CIRP or HMGB1 for $6 \mathrm{~h}$. (k) mtDNA damage measured by RT-PCR in BMDM stimulated with BCM $(40 \mu \mathrm{l} / \mathrm{ml})$, CIRP (10 $\mu \mathrm{g} / \mathrm{ml})$, or HMGB1 $(10 \mu \mathrm{g} / \mathrm{ml})$, which combined with or without lgG isotype antibody (10 $\mu \mathrm{g} / \mathrm{ml})$ or CIRP neutralizing antibody $(10 \mu \mathrm{g} / \mathrm{ml})$ for $24 \mathrm{~h}$. (I) Quantification of mtDNA by RT-PCR with three specific mitochondrial primers (Mt-1/2/3) in J774.2 cells treated with $100 \mathrm{ng} / \mathrm{ml}$ ethidium bromide (EtBr) for 0-14 days. (m) mtDNA fold induction quantified by RT-PCR in J774.2 cells +/ - pretreatment with $100 \mathrm{ng} / \mathrm{ml}$ EtBr for 7 days, and stimulation with BCM $(40 \mu \mathrm{l} / \mathrm{ml}$ ) for 0,6 , and $24 \mathrm{~h}$. (n) Confocal images and quantification of fragemented DNA (TUNEL; red) and Hoechst nuclear staining of J774.2 cells $+/-$ pretreatment with $100 \mathrm{ng} / \mathrm{ml} \mathrm{EtBr}$ for 7 days, and stimulated with BCM $(40 \mu / \mathrm{ml})$ for 0,6 , and $24 \mathrm{~h}$. All results are representative of three independent experiments. The graph shows the mean and S.E.M., $n=3$. Significances between groups were determined by using independent samples two-tailed Student's $t$-test. ${ }^{*} P<0.05$ or ${ }^{* *} P<0.01$ versus the control or indicates groups. NS, no significant difference 
a
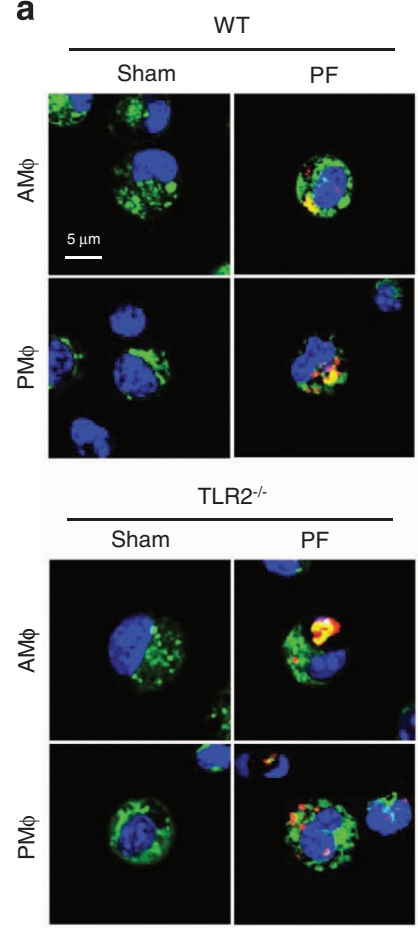

MitoTracker TUNEL Hoechst
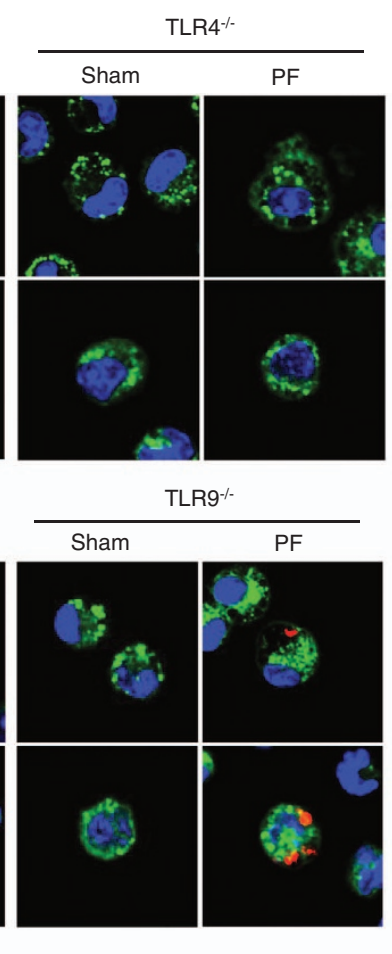

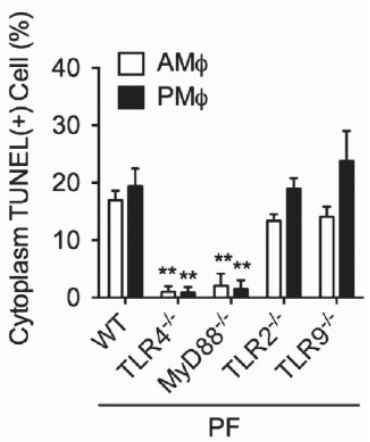

b
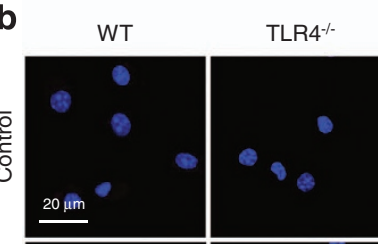

MyD88--
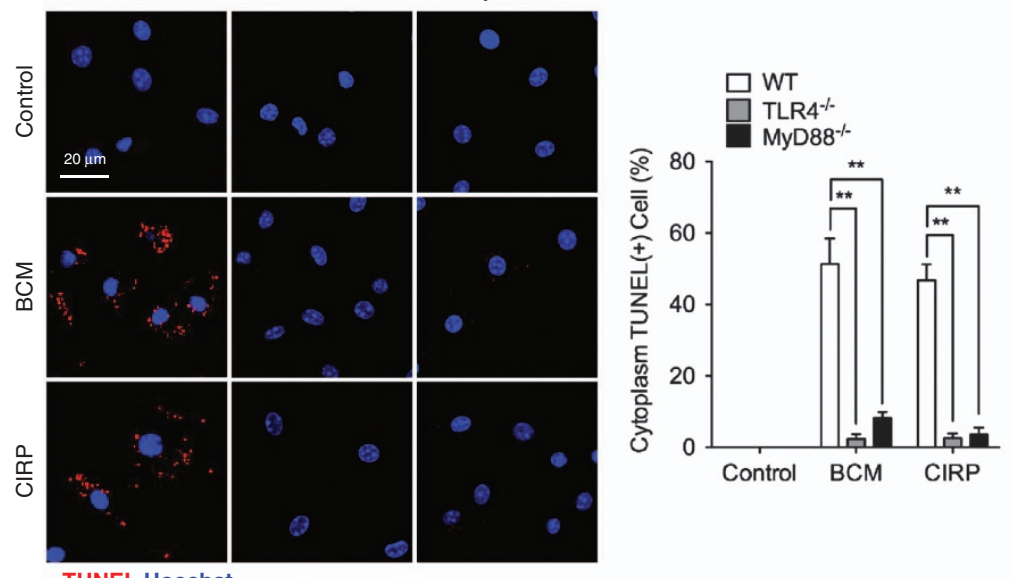

TUNEL Hoechst

C
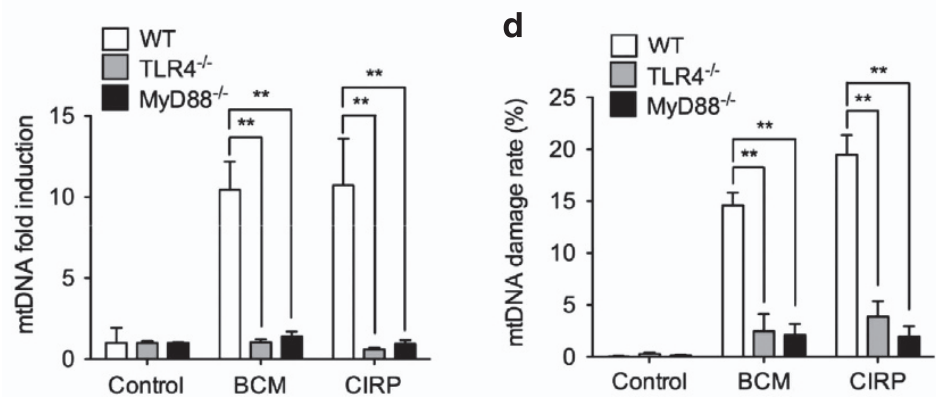

Figure 3 BCM-induced mtDNA fragmentation is mediated by TLR4-MyD88 signaling. (a) Confocal images and analysis of AM $\phi$ and PM $\phi$ harvested from WT, TLR4 ${ }^{-1-}$,

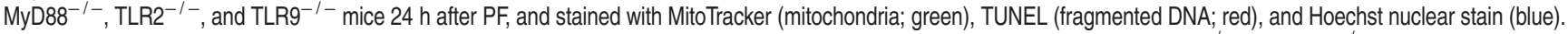
(b) Confocal images and analysis of TUNEL (fragmented DNA; red) and Hoechst nuclear stain (blue) in BMDM isolated from WT, TLR4 ${ }^{-1-}$, or MyD88 ${ }^{-1-}$ mice and treated with BCM $(40 \mu / / \mathrm{ml})$ or CIRP $(10 \mu \mathrm{g} / \mathrm{ml})$ for $24 \mathrm{~h}$. (c) mtDNA fold induction and (d) mtDNA damage measured by RT-PCR in WT, TLR4 ${ }^{-1-}$, or MyD88 ${ }^{-1-}$ BMDM treated with BCM $(40 \mu \mathrm{l} / \mathrm{ml})$ for 0,6 , and $24 \mathrm{~h}$. All results are representative of three independent experiments. The graphs show the mean and S.E.M., $n=3$. Significances between groups were determined by using independent samples two-tailed Student's $t$-test. ${ }^{*} P<0.05$ or ${ }^{* *} P<0.01$ compares with WT groups or between the indicated groups 
$\mathrm{BCM}$
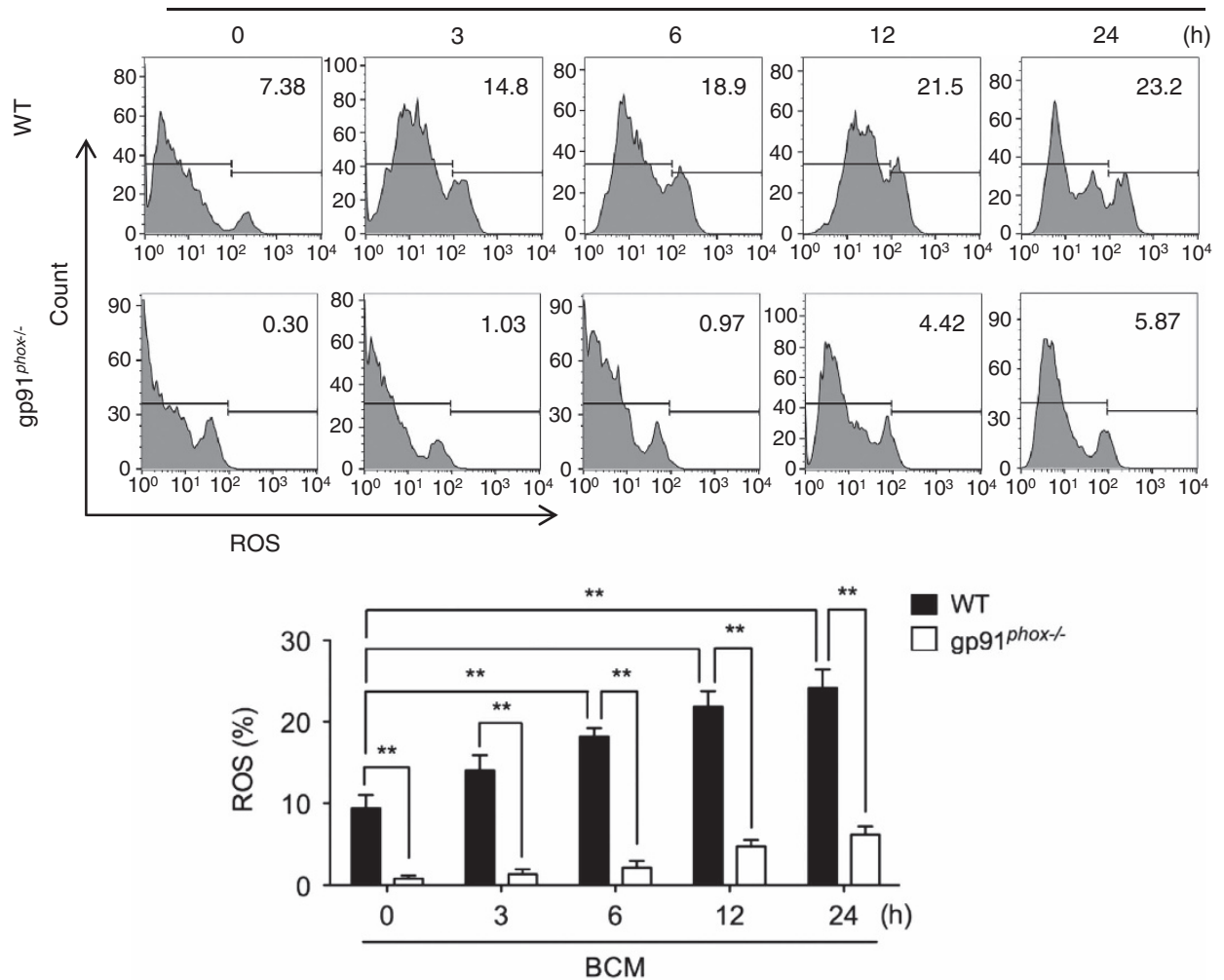

b

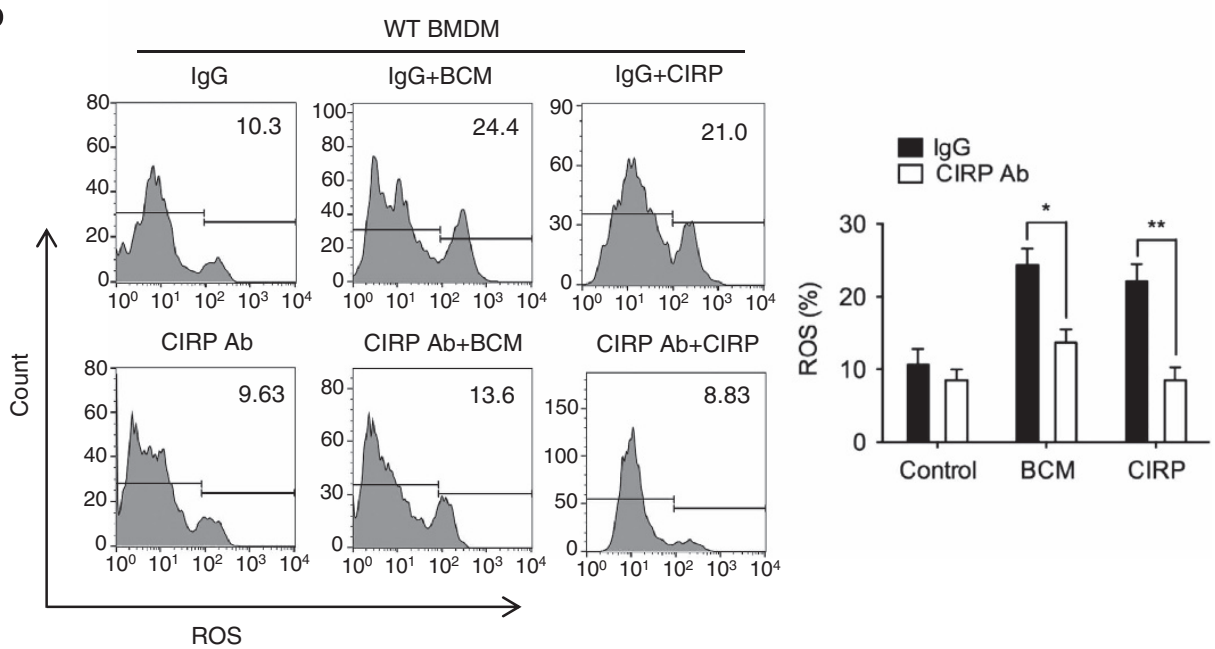

Figure 4 ROS mediates mtDNA fragmentation. (a) Flow cytometric plots and analysis of DCF fluorescence (ROS) in WTor gp91 ${ }^{\text {phox }-/-}$ BMDM stimulated with $40 \mu / / m l$ of BCM for 0-24 h. (b) Flow cytometric plots and analysis of DCF fluorescence in WT BMDM treated with $40 \mu \mathrm{l} / \mathrm{ml} \mathrm{BCM}$ or $10 \mu \mathrm{g} / \mathrm{ml} \mathrm{CIRP} \mathrm{for} 24 \mathrm{~h}+1-\operatorname{lgG}$ isotype antibody (10 $\mu \mathrm{g} /$ $\mathrm{ml}$ ) or CIRP neutralizing antibody $(10 \mu \mathrm{g} / \mathrm{ml})$. (c) Flow cytometric plots and analysis of DCF fluorescence (ROS) in gp91 ${ }^{\text {phox }-/-}$ BMDM treated with $10 \mu \mathrm{g} / \mathrm{ml}$ CIRP for 0-24 h. (d) Western blot to show p47 $7^{\text {phox }}$ phosphorylation up to $3 \mathrm{~h}$ after stimulation with BCM (40 $\left.\mu / / \mathrm{ml}\right)$. (e) Immunoprecipitation (IP) with anti-p47 $7^{\text {phox }}$ and immunoblot for gp91 ${ }^{\text {phox }}$ in lysates from WT BMDM treated with BCM for 0-18 h. (f) Confocal images and analysis of TUNEL and Hoechst staining in WTor gp9 $1^{\text {phox }-1-}$ BMDM stimulated by $40 \mu / / \mathrm{ml} \mathrm{BCM}$ or $10 \mu \mathrm{g} / \mathrm{ml}$ CIRP for $24 \mathrm{~h}$. (g) mtDNA fold induction and (h) mtDNA damage measured by RT-PCR in WTor gp91 ${ }^{\text {phox }-/-}$ BMDM treated with BCM (40 $\left.\mu / / \mathrm{ml}\right)$ for 0,6 , and $24 \mathrm{~h}$. All results are representative of three independent experiments. The graphs show the mean and S.E.M., $n=3$. Significances between groups were determined by using independent samples two-tailed Student's $t$-test. ${ }^{\star} P<0.05$ or ${ }^{\star \star} P<0.01$ compared with control groups or indicated groups

Autophagy is known as a major regulator of removal of damaged mitochondria through mitophagy. ${ }^{41,42}$ Next, we addressed whether BCM-induced mtDNA fragmentation activates autophagy. First, a time-course study showed that BCM treatment of BMDM increased LC3-II expression at $24 \mathrm{~h}$ (Figure 6a). LC3-II is the activated form of LC3 that is incorporated in autophagosomes. ${ }^{43}$ Second, CIRP neutralizing antibody suppressed LC3-II formation in response to BCM and CIRP (Figure 6b). Third, there was very little formation of LC3-II in gp91 ${ }^{\text {phox }-1-}$ BMDM after BCM or CIRP treatment compared with WT BMDM (Figure 6c). Similarly, mtDNA depletion in $\mathrm{J} 774.2$ cells prevented BCM-induced 
c

gp91 ${ }^{\text {phox--/-BMDM }}$
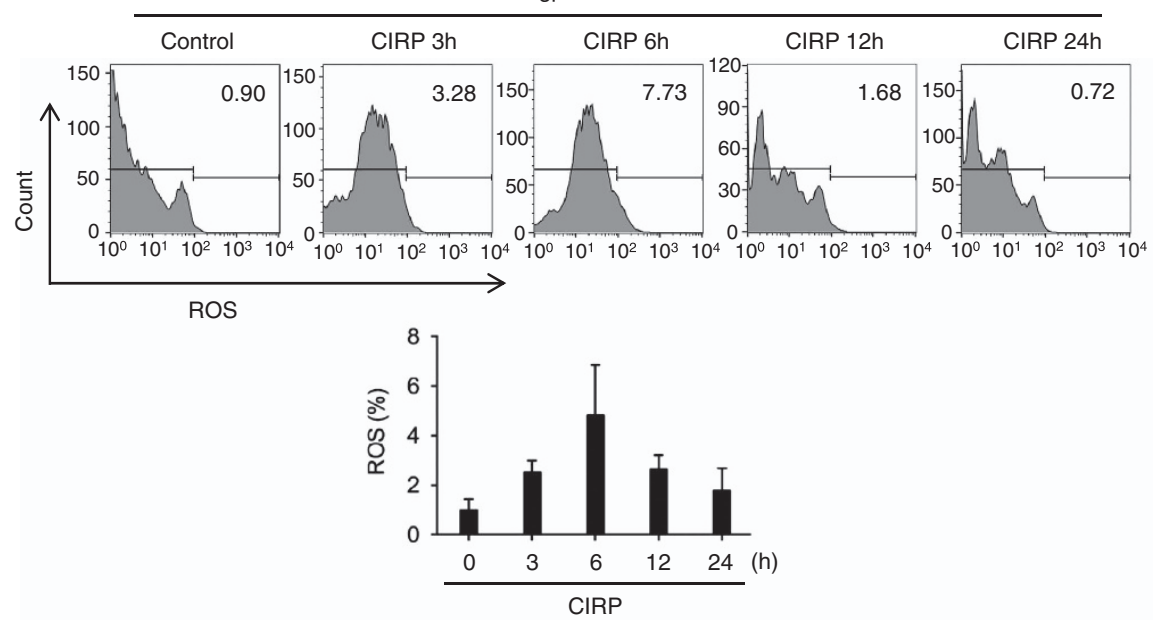

d

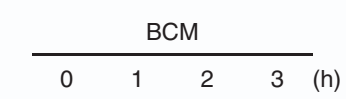

e

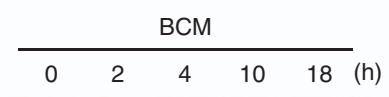

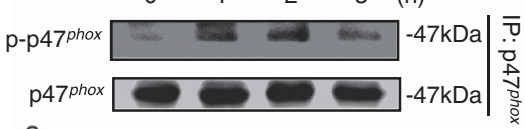
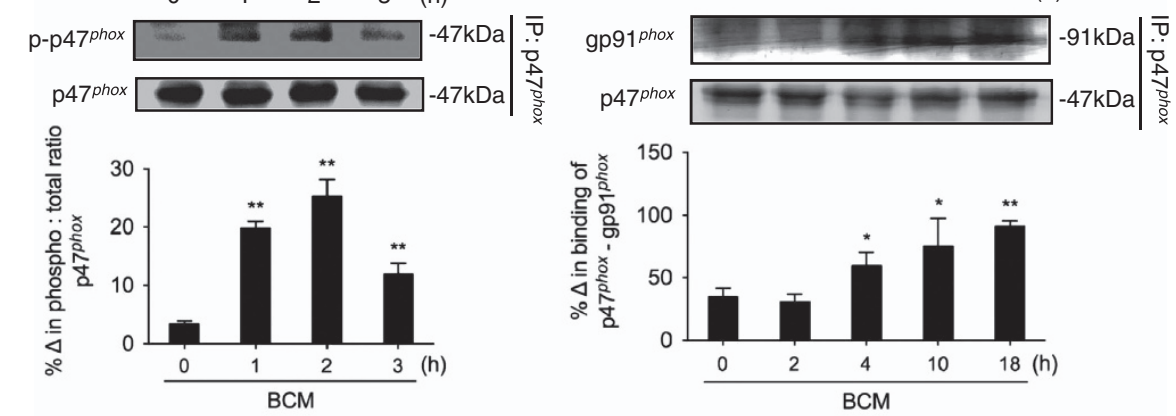

f

Control $\quad \mathrm{BCM}$ CIRP
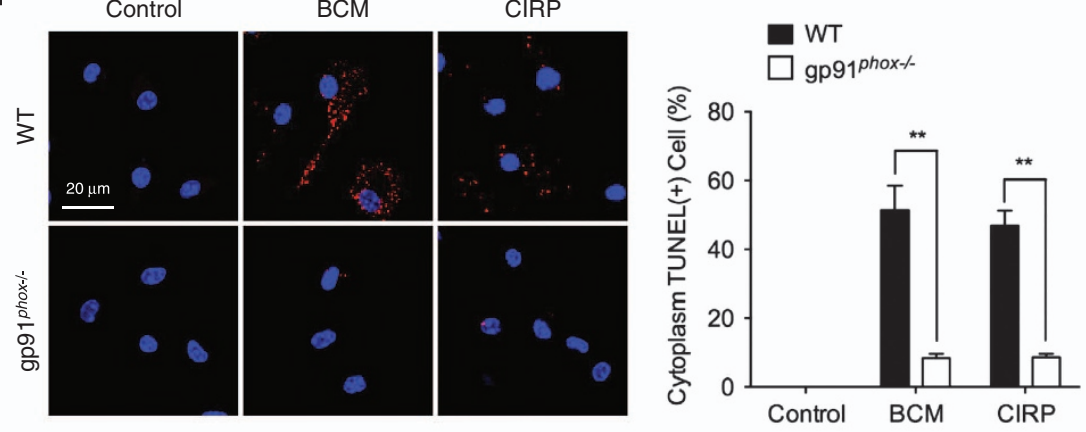

TUNEL Hoechst
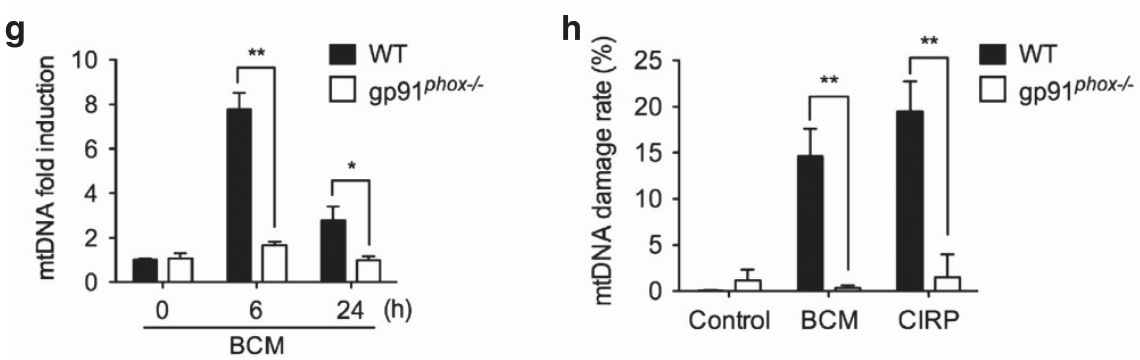

Figure 4 Continued. 
a
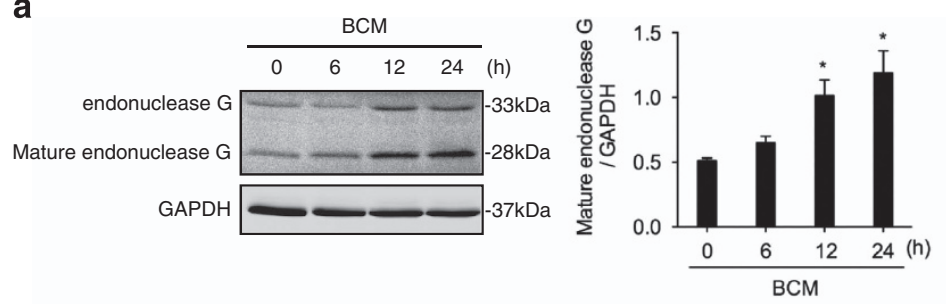

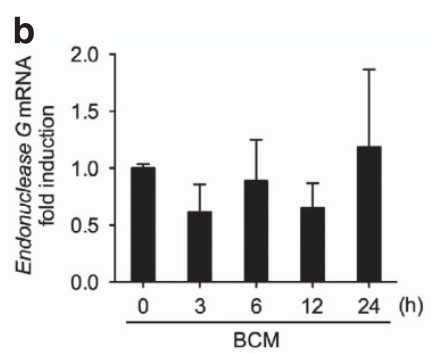

C
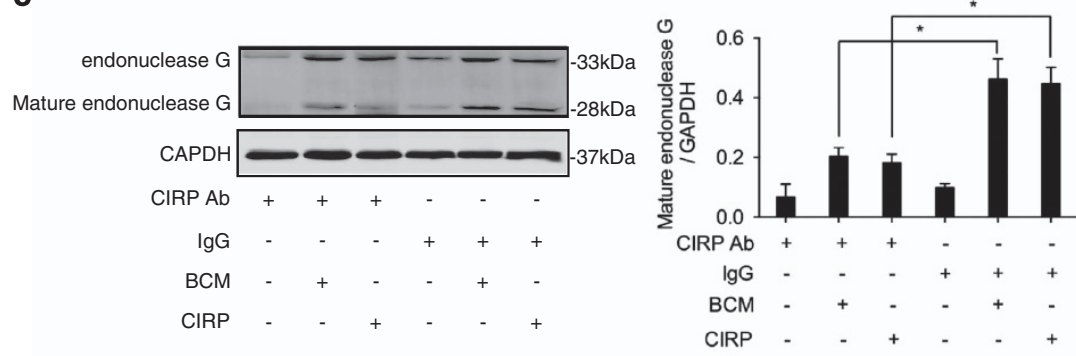

d
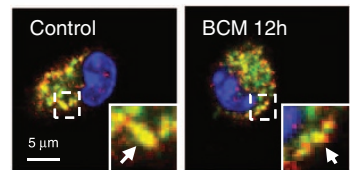

MitoTracker Endonuclease G Hoechst

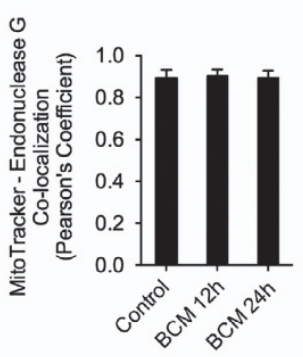

f
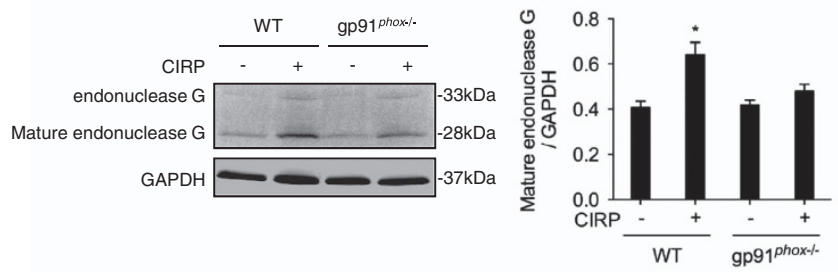

e
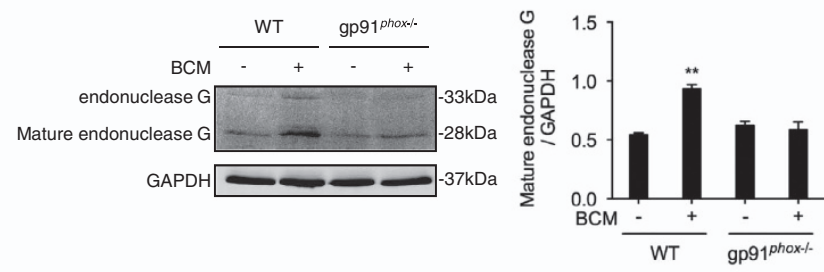
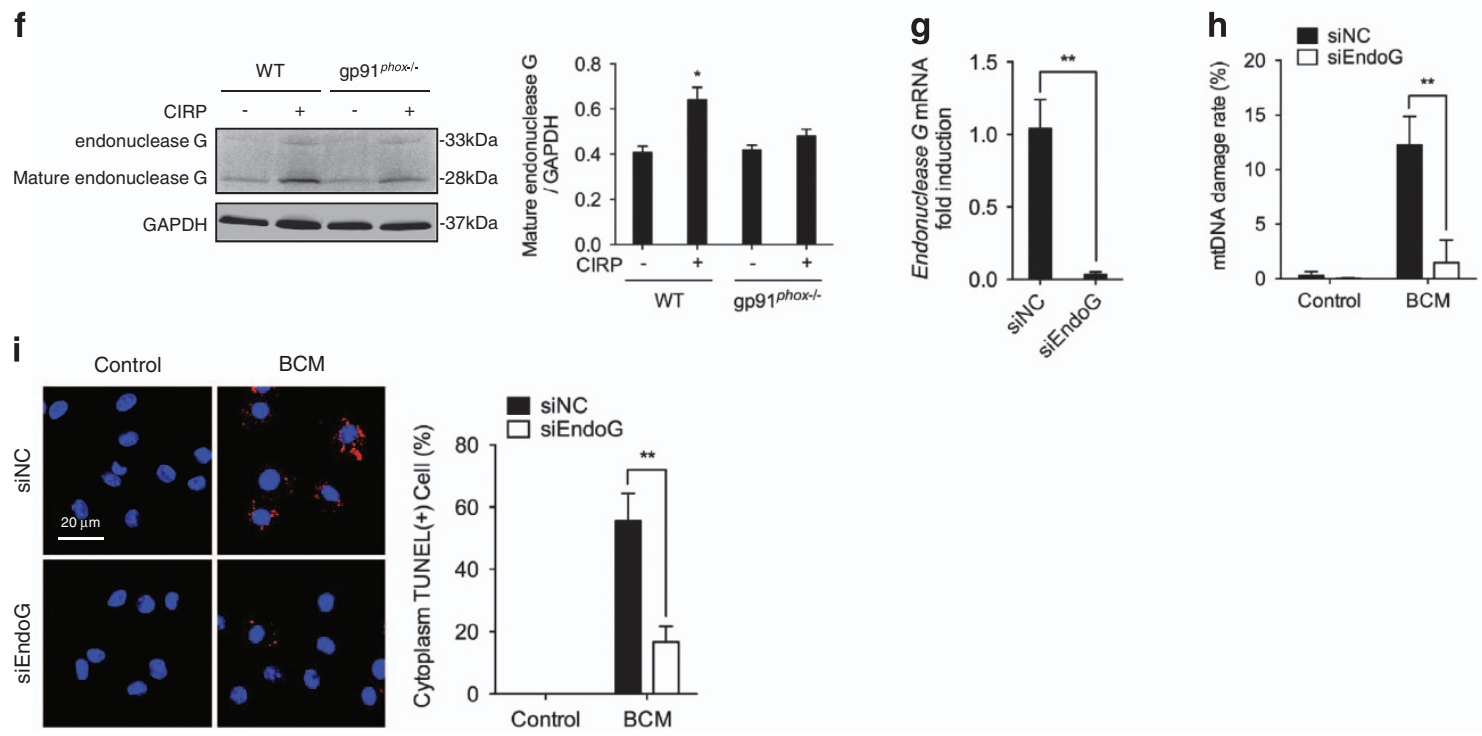

TUNEL Hoechst

Figure 5 Endonuclease $\mathrm{G}$ fragments mtDNA in $\mathrm{M} \phi$ after $\mathrm{BCM}$ treatment. (a) Western blot of whole-cell lysates showing endonuclease $\mathrm{G}$ protein expression and (b) mRNA expression in BMDM stimulated by $40 \mu \mathrm{l} / \mathrm{ml} \mathrm{BCM}$ for $0-24 \mathrm{~h}$. (c) Western blot of whole-cell lysates showing endonuclease $\mathrm{G}$ protein expression in BMDM treated with $40 \mu \mathrm{l} / \mathrm{ml}$ $\mathrm{BCM}$ or $10 \mu \mathrm{g} / \mathrm{ml}$ CIRP for $24 \mathrm{~h}+/-$ CIRP neutralizing antibody $(10 \mu \mathrm{g} / \mathrm{ml})$ or lgG isotype antibody $(10 \mu \mathrm{g} / \mathrm{ml})$. (d) Confocal immunofluorescence images and analysis of colocalization of mitochondria (MitoTracker; green) and endonuclease G (red) in BMDM treated with $40 \mu \mathrm{l} / \mathrm{ml}$ BCM for 12 or $24 \mathrm{~h}$. Arrows indicate the colocalization of mitochondria and endonuclease G. (e) Western blot of whole-cell lysates showing endonuclease G expression in WT or gp91 ${ }^{\text {phox }-1-}$ BMDM stimulated by $40 \mu l / \mathrm{ml} \mathrm{BCM}$ or (f) stimulated with $10 \mu \mathrm{g} / \mathrm{ml} \mathrm{CIRP}$ for $24 \mathrm{~h}$. (g) Endonucleases G mRNA expression in BMDM transfected with control non-coding siRNA (siNC) or siRNA specific for endonuclease G (siEndoG) for 24 h. (h) mtDNA damage and (i) confocal images and analysis of TUNEL staining (fragmented DNA; red) and nuclear Hoechst staining (blue) in WT BMDM transfected with siNC or siEndoG and stimulated by $40 \mu / / \mathrm{ml} \mathrm{BCM}$ for $24 \mathrm{~h}$. All results are representative of three independent experiments. The graphs show the mean and S.E. M., $n=3$. Significances between groups were determined by using independent samples two-tailed Student's $t$-test. ${ }^{*} P<0.05$ or ${ }^{* *} P<0.01$ compared with control groups or indicated groups 
LC3-II formation (Figure 6d). To confirm our findings, we also visualized colocalization of LC3 with TUNEL staining in the BMDM treated with BCM or CIRP. Figure 6 e shows that both $\mathrm{BCM}$ and CIRP can induce LC3 colocalization with TUNEL- positive fragmented DNA. As expected from our results above, when mtDNA was depleted in $\mathbf{J} 774.2$ cells, there was no TUNEL staining in the cytoplasm, and so no localization of TUNEL with LC3 (Figure 6f). These observations suggest

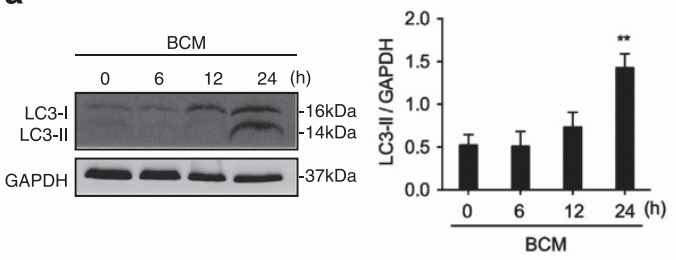

b

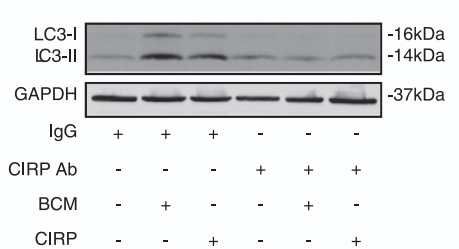

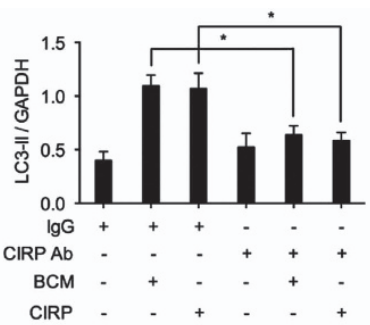

e

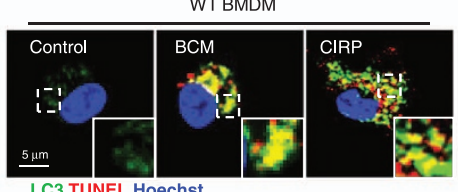

LC3 TUNEL Hoechst

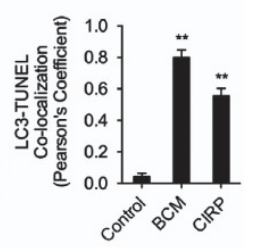

C
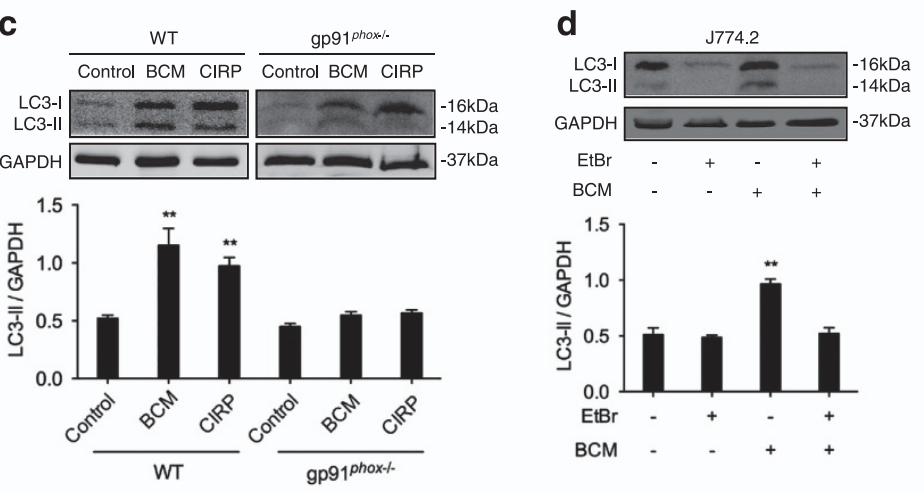

f
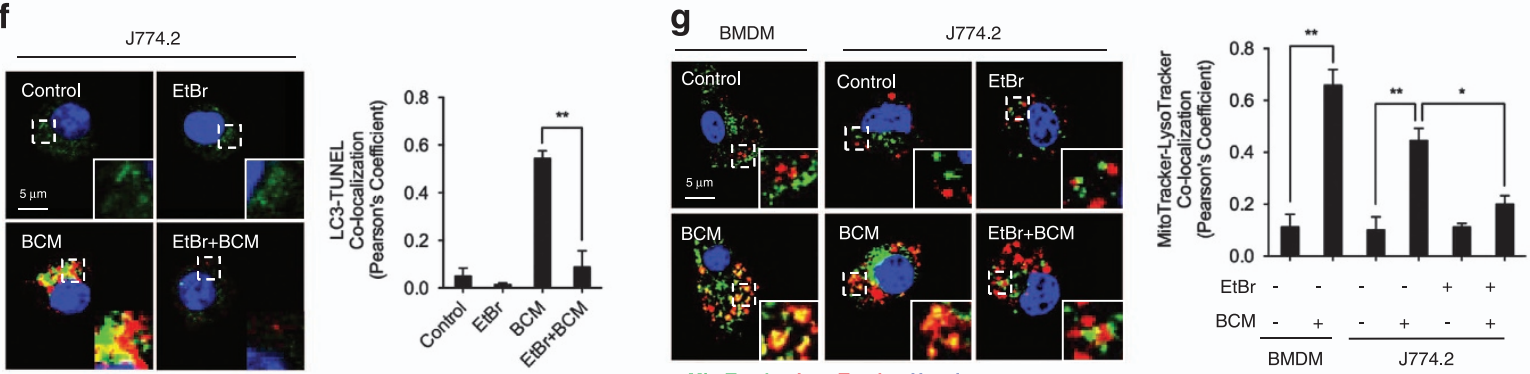

LC3 TUNEL Hoechst

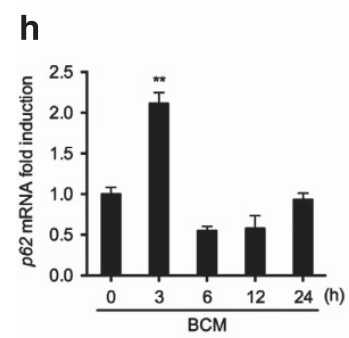

i

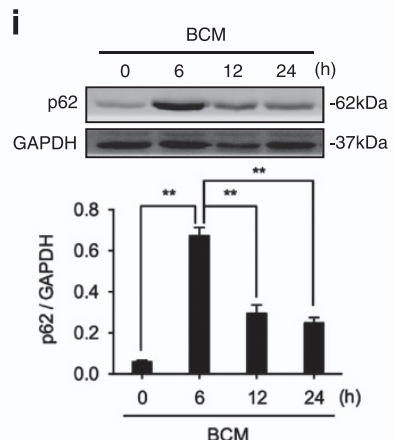

j
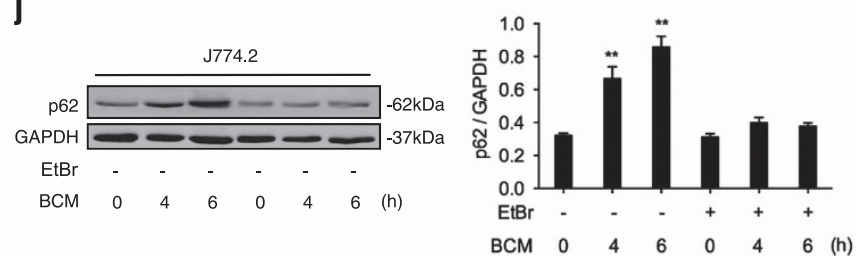

$\mathbf{k}$
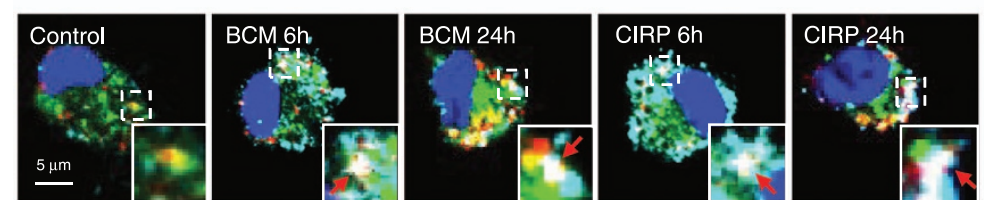

MitoTracker LC3 p62 Hoechst 
fragmented mtDNA induces and localizes to the autophagosome.

In addition, as Figure $6 \mathrm{~g}$ shows, BCM also induced mitophagy in BMDM, which can be identified as colocalization of mitochondria (MitoTracker) and lysosomes (LysoTracker). However, this induction of mitophagy was prevented in mtDNA-depleted $\mathbf{J} 774.2$ cells (Figure $6 \mathrm{~g}$ ).

The degradation of $p 62$ is often used as an indicator of autophagy. ${ }^{44} \mathrm{BCM}$ induced increases in expression of $\mathrm{p} 62$ mRNA at $3 \mathrm{~h}$ (Figure 6h) and in p62 protein expression at $6 \mathrm{~h}$ (Figure 6i), which is then followed by decreases in p62 protein expression at 12 and $24 \mathrm{~h}$ suggesting activation of autophagy pathways and clearance of p62 (Figure 6i). However, in mtDNA-depleted J774.2 cells BCM failed to induce p62 upregulation (Figure 6j). Again, colocalization of mitochondria, LC3, and p62 following BCM or CIRP stimulation for $24 \mathrm{~h}$ was visualized by confocal microscopy as shown in Figure 6k. Taken together, these data suggest that BCM- and CIRP-induced mtDNA fragmentation leads to mitophagy.

\begin{abstract}
Autophagy prevents fragmented mtDNA-induced macrophage necroptosis. Autophagy is one of the critical mechanisms for the clearance of damaged mtDNA, so it is important for cellular homeostasis. ${ }^{45}$ We next determined the role of autophagy in regulation of cell fate in response to mtDNA fragmentation. In $\mathrm{LC}^{-1-} \mathrm{BMDM}$, in which autophagosomes cannot be induced by mtDNA fragmentation, BCM-induced cell death significantly increased compared with WT BMDM (Figure 7a). To further define the type of the cell death occurring, we measured RIPK1 phosphorylation, as well as colocalization of RIPK1 and RIPK3, which are features of necroptosis. ${ }^{46}$ We found that BCM treatment induced higher levels of RIPK1 phosphorylation in $\mathrm{LC}^{-/-}$ BMDM (Figure 7b), and increased colocalization of RIPK1 and RIPK3 compared with WT BMDM (Figure 7c). Addition of the necroptosis inhibitor necrostatin-1 (Nec-1) significantly blocked BCM- or CIRP-induced cell death in $\mathrm{LC}^{-1-}$ BMDM (Figure 7d). These data reveal an important role for autophagy in preventing necroptosis following mtDNA damage.
\end{abstract}

Necroptotic $M \phi$ induce inflammatory responses in naive Мф. BCM induced necroptosis in $\mathrm{LC}^{-/}-\mathrm{BMDM}$ and necroptosis is well known as a form of inflammatory cell death. ${ }^{47,48}$ To determine the significance of mtDNA fragmentation-induced autophagy in maintaining cellular homeostasis, we investigated the effect of necroptotic M $\phi$ on neighboring healthy M $\phi$. WT or $\mathrm{LC}^{-/-} \mathrm{BMDM}$ were pretreated with BCM for $24 \mathrm{~h}$, and then were cocultured with naive macrophages for 6 or $18 \mathrm{~h}$. As shown in Figure 8, the BCM-pretreated $\mathrm{LC}^{-1-} \mathrm{BMDM}$, which lack autophagy and exhibit necroptosis, significantly increased inflammatory responses in naive macrophages, including increased IL-1 $\beta$ and NOS2 mRNA expression at $6 \mathrm{~h}$, and increased $\mathrm{IL}-1 \beta$, IL- 6 and TNF- $a$ mRNA at $18 \mathrm{~h}$. These results suggest that mtDNA fragmentation-induced autophagy plays a protective role in limiting local inflammation through the regulation of cell death.

\section{Discussion}

The mechanisms behind trauma/tissue damage regulation of innate immune responses are not yet fully defined. ${ }^{16}$ Our current study explored a mechanism underlying traumainduced regulation of $M \phi$ death, in which CIRP released from damaged tissue acts through TLR4-MyD88 signaling to induce $M \phi m t D N A$ fragmentation, via a pathway in which NADPH oxidase-derived ROS served as a major mediator for the induction of endonuclease $\mathrm{G}$, which, in turn, directly mediates mtDNA fragmentation. Fragmented mtDNA then triggered $M \phi$ autophagy and necroptosis through separate pathways, although autophagy also suppressed M $\phi$ necroptosis, to attenuate propagation of local inflammation (Figure 9).

Previous studies have shown that during injury extracellular mtDNA serves as a DAMP that induces inflammatory response through TLR9 signaling. ${ }^{23,49,50}$ However, the mechanism of intracellular mtDNA damage had not been fully identified. In our current study, we revealed an important role for intracellular fragmented mtDNA in regulating $M \phi$ death and inflammation.

We defined fragmented DNA in M $\phi$ cytoplasm after BCM treatment as damaged mtDNA based on the facts that: (1) predeleting exogenous DNA in BCM using nuclease did not prevent the formation of fragmented DNA in M $\phi$ cytoplasm (Figures 2a and b); (2) fragmented DNA was not endosomal, suggesting it had not been endocytosed (Figure 2c); (3) DNAfree recombinant CIRP induced cytoplasmic fragmented DNA in $\mathrm{M} \phi$ (Figures 2i and j); (4) BCM treatment induced changes in

Figure 6 Fragmented mtDNA induces macrophage autophagy. (a) Western blot of whole-cell lysates showing LC3 expression in BMDM stimulated by $40 \mu / / m l ~ B C M$ for $0-$ $24 \mathrm{~h}$. GAPDH used as loading control. (b) Western blot of whole-cell lysates showing LC3 expression in BMDM treated with $40 \mu \mathrm{l} / \mathrm{ml} \mathrm{BCM}$ or $10 \mu \mathrm{g} / \mathrm{ml} \mathrm{CIRP}$ for $24 \mathrm{~h}+/-\mathrm{lgG}$ isotype antibody $(10 \mu \mathrm{g} / \mathrm{ml})$ or CIRP neutralizing antibody $(10 \mu \mathrm{g} / \mathrm{ml})$. (c) Western blot of whole-cell lysates showing LC3 expession in WTor gp91 ${ }^{\text {phox }-/-}$ BMDM stimulated by $40 \mu \mathrm{l} / \mathrm{ml} \mathrm{BCM}$ or $10 \mu \mathrm{g} / \mathrm{ml} \mathrm{CIRP}$ for $24 \mathrm{~h}$. (d) Western blot of whole-cell lysates showing LC3 expression in $\mathrm{J} 774.2$ cells $+/-$ pretreatment with $100 \mathrm{ng} / \mathrm{ml}$ EtBr for 7 days, and stimulated with BCM $(40 \mu \mathrm{l} / \mathrm{ml}$ ) for $24 \mathrm{~h}$. (e) Confocal immunofluorescence images and analysis showing colocalization of LC3 (autophagosome; green) and TUNEL (fragmented DNA; red) and Hoechst nuclear stain (blue) in BMDM treated with $40 \mu \mathrm{l} / \mathrm{ml} \mathrm{BCM}$ or $10 \mu \mathrm{g} / \mathrm{ml}$ CIRP for $24 \mathrm{~h}$. (f) Confocal immunofluorescence images and analysis of colocalization of LC3 (autophagosome; green) and TUNEL (fragmented DNA; red) and Hoechst nuclear stain (blue) in J774.2 cells +l - pretreatment with $100 \mathrm{ng} / \mathrm{ml}$ EtBr for 7 days, and stimulated with BCM $(40 \mu \mathrm{l} / \mathrm{ml})$ for $24 \mathrm{~h}$. (g) Confocal immunofluorescence images showing colocalization of mitochondria (MitoTracker; green) and lysosomes (LysoTracker; red) in BMDM, or J774.2 cells +l - pretreatment with $100 \mathrm{ng} / \mathrm{ml} \mathrm{EtBr}$ for 7 days, and stimulated with BCM (40 $\mu$ l/ml) for $24 \mathrm{~h}$. (h) Expression levels of p62 $\mathrm{mRNA}$ or (i) protein expression in BMDM stimulated by BCM $(40 \mu \mathrm{l} / \mathrm{ml})$ for 0-24 h. (j) Western blot of whole-cell lysates showing p62 protein expression in $\mathrm{J} 774.2 \mathrm{cells}+\mathrm{l}-\mathrm{pretreatment}$ with $100 \mathrm{ng} / \mathrm{ml} \mathrm{EtBr}$ for 7 days, then stimulated with BCM $(40 \mu \mathrm{l} / \mathrm{ml})$ for $0-6 \mathrm{~h}$. (k) Confocal immunofluorescence images and analysis of colocalization of mitochondria (MitoTracker; green), LC3(autophagosomes; red) and p62 (cyan) in BMDM stimulated with BCM (40 $\mu \mathrm{l} / \mathrm{ml})$ or CIRP (10 $\mu \mathrm{g} / \mathrm{ml})$ for $24 \mathrm{~h}$. Arrows indicate the colocalization of mitochondria-LC3-p62 (white). All results are representative of three independent experiments. The graphs show the mean and S.E.M., $n=3$. Significances between groups were determined by using independent samples two-tailed Student's $t$-test. ${ }^{*} P<0.05$ and ${ }^{* *} P<0.01$ versus the control or compared between the indicated groups 
a

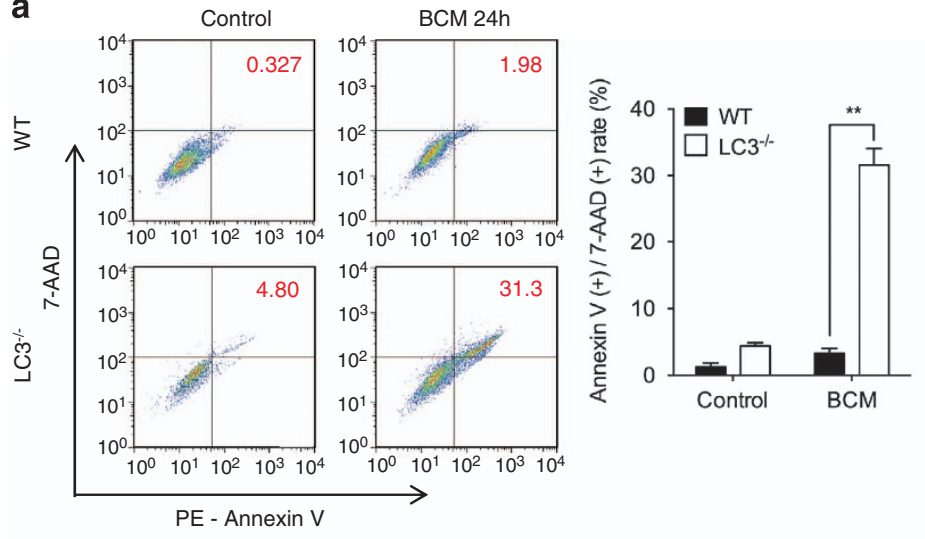

b

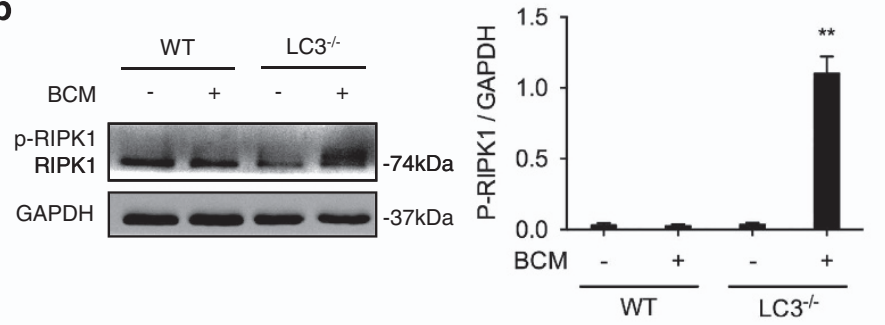

C
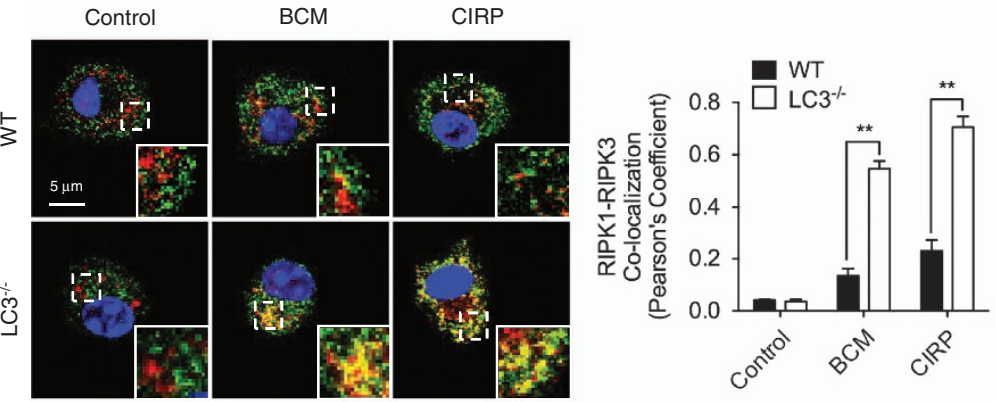

RIPK1 RIPK3 Hoechst

d
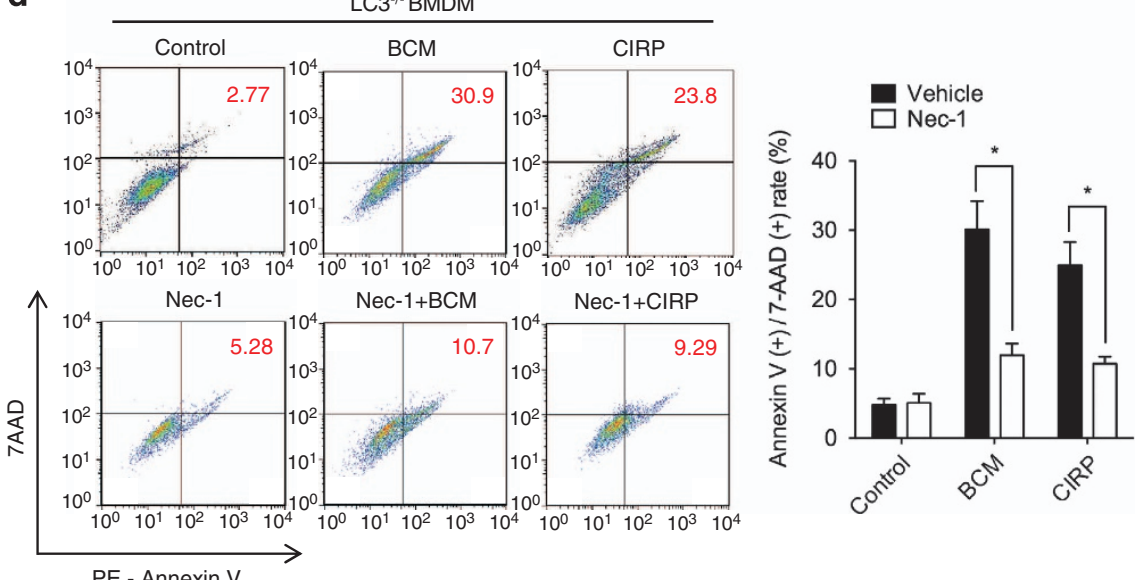

$P E$ - Annexin V

Figure 7 Autophagy prevents fragmented mtDNA-induced macrophage necroptosis. (a) Flow cytometric plots and analysis of cell death (AnnexinV-positive, 7-AAD-positive)

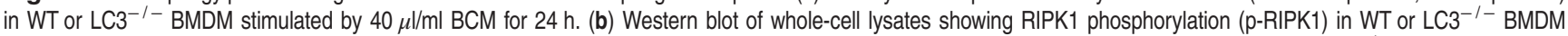
stimulated by $40 \mu / / \mathrm{ml} \mathrm{BCM}$ for $24 \mathrm{~h}$. (c) Confocal microscopy images and analysis showing colocalization of RIPK1 (green) and RIPK3 (red) in WTor LC3 ${ }^{-1}-$ BMDM treated with $\mathrm{BCM}(40 \mu \mathrm{l} / \mathrm{ml})$ or CIRP $(10 \mu \mathrm{g} / \mathrm{ml})$ for $24 \mathrm{~h}$. (d) Flow cytometric plots and analysis of cell death (AnnexinV-positive, 7-AAD-positive) in LC3 ${ }^{-1-}$ BMDM treated with BCM (40 $\mu$ l/ $\mathrm{ml}$ ) or CIRP $(10 \mu \mathrm{g} / \mathrm{ml})+/-30 \mu \mathrm{M}$ necrostatin-1 (Nec-1) for $24 \mathrm{~h}$. All results are representative of three independent experiments. The graphs show the mean and S.E.M., $n=3$. Significances between groups were determined by using independent samples two-tailed Student's $t$-test. ${ }^{\star} P<0.05$ or ${ }^{\star \star} P<0.01$ compared with control groups or indicated groups 


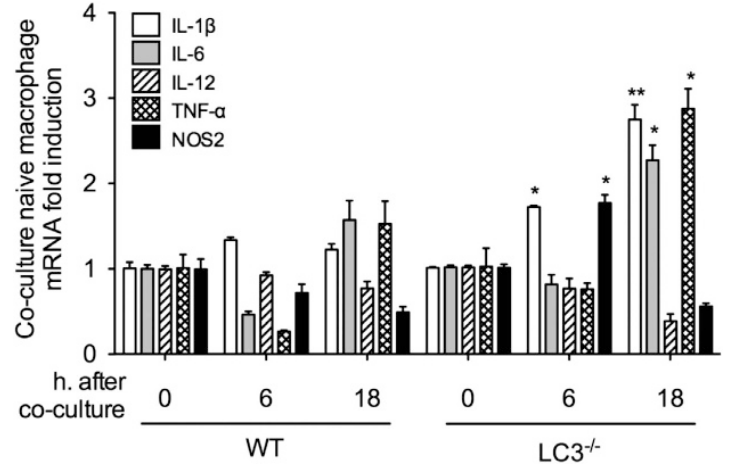

Figure 8 Necroptotic $\mathrm{M} \phi$ induce inflammatory responses in naive M $\phi$. mRNA expression of IL1 $\beta$, IL-6, IL-12, TNF- $\alpha$, and NOS2 in naive BMDM placed in the bottom of a Transwell plate, with WT or $\mathrm{LC}^{-1-}$ BMDM pre-stimulated by BCM $(40 \mu / / \mathrm{ml})$ for $24 \mathrm{~h}$ in the upper wells. Cells were then cocultured for $0-18 \mathrm{~h}$. All results are representative of three independent experiments. The graphs show the mean and S.E.M., $n=3$. Significances between groups were determined by using independent samples two-tailed Student's $t$-test. ${ }^{*} P<0.05$ and ${ }^{* *} P<0.01$ compared with control groups

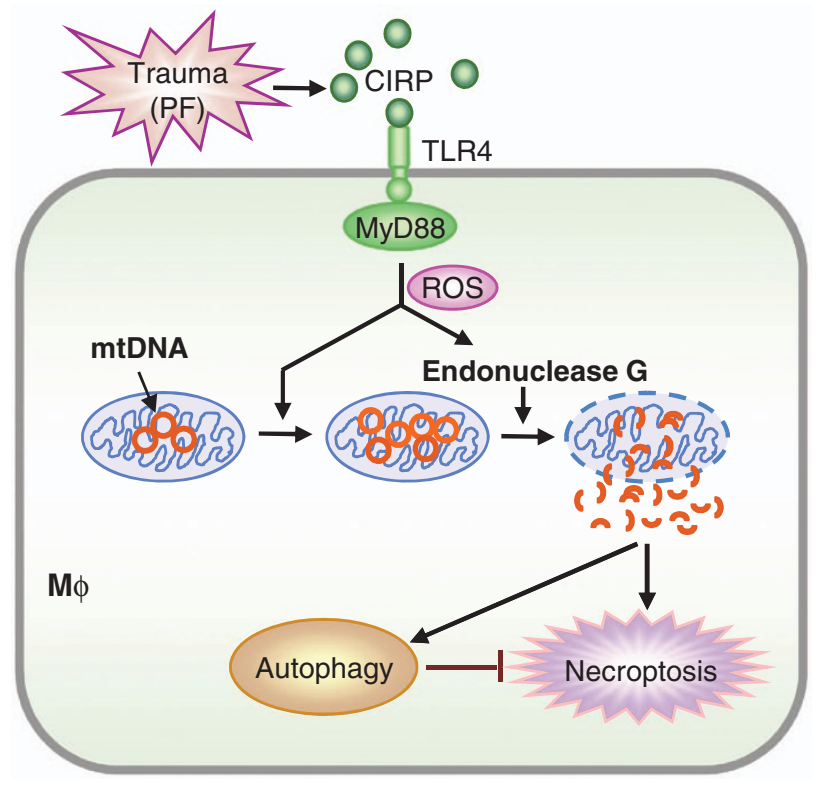

Figure 9 Model of trauma-induced mtDNA fragmentation regulating macrophage death. PF or BCM through CIRP-TLR4-MyD88 signaling induces NADPH oxidase activation and release of ROS, which activate endonuclease $\mathrm{G}$. Endonuclease $\mathrm{G}$ directly fragments mtDNA, which triggers $\mathrm{M} \phi$ autophagy, as well as necroptosis by separate pathways. However, autophagy also suppresses $M \phi$ necroptosis to limit local inflammation

mtDNA synthesis and degradation (Figures 2e-g); and (5) depletion of mtDNA with EtBr prevented cytoplasmic fragmented DNA in M $\phi$ in response to BCM (Figures 2I-n). We also demonstrated a dynamic alteration in mtDNA quantity after BCM treatment with increased mtDNA in the early phase $(6 \mathrm{~h})$, followed by decreased levels in the late phase $(24 \mathrm{~h})$. Overall we detected about $15 \%$ mtDNA damage, an indication of mtDNA fragmentation. The observations that CIRP induced mtDNA fragmentation and neutralizing antibody against CIRP prevented the mtDNA fragmentation in response to $\mathrm{BCM}$ indicate that CIRP is one of the major components in damaged tissue to induce mtDNA fragmentation.

Our previous studies showed that TLR4-MyD88 signaling mediates NADPH oxidase activation in neutrophils and lung vascular endothelial cells in response to hemorrhagic shock and LPS. ${ }^{37,51,52}$ In the current study, we showed that the PF/tissue damage activation of TLR4-MyD88 signaling results in increases in ROS production through the activation of NADPH oxidase in M $\phi$. It is noticeable that LPS, CIRP, and HMGB1, all being TLR4 agonists, induce very different responses in terms of DNA damage. For example, LPS causes DNA fragmentation in the nucleus, and CIRP in the mitochondria; HMGB1 did induce DNA fragmentation in the nucleus, though perhaps not as much as LPS. This raises a fundamental biological question on how limited receptor classes can induce such a broad range of different cellular responses, which has generated several hypotheses. A plausible hypothesis is that following receptor activation, different signaling pathways selectively adopt different adaptor proteins to induce different downstream outcomes. It can be assumed that CIRP, HMGB1, and LPS bind to different domain structures of TLR4, which then induce different TLR4 conformational changes and activate different signaling pathways. Indeed, this is an open question that remains to be further elucidated.

The identity of the executor protein downstream of ROS that cleaved mtDNA was not clear. ${ }^{35}$ Previous studies showed that endonuclease $\mathrm{G}$ can be activated under oxidative stress ${ }^{53-55}$ and then functions as a chromosomal DNA fragmentation enzyme. ${ }^{26,56}$ Studies have also shown that endonuclease $G$ plays a critical role in paternal mtDNA degradation during animal development. ${ }^{27,39}$ In this study, we demonstrated that the endonuclease $\mathrm{G}$ is an important executor for induction of mtDNA fragmentation, and ROS is required for its activation. Genetic deletion of the NADPH oxidase subunit gp9 $1^{\text {phox }}$ significantly diminished BCM- and CIRP-induced endonuclease $G$ activation, and knockdown of endonuclease $G$ prevented BCM-induced mtDNA damage and appearance of mtDNA fragmentation in $\mathrm{M} \phi$ cytoplasm.

The current study further determined the protective effect of autophagy in PF/tissue damage. We identified that fragmented mtDNA induces autophagy, which serves as a mechanism to clear the damaged mtDNA. In $\mathrm{LC}^{-/-} \mathrm{BMDM}$, which cannot initiate the autophagosome formation, the damaged mtDNA promotes the $M \phi$ necroptosis, which propagates and enhances inflammatory responses by activating neighboring innate immune cells. These observations indicate an important role for autophagy in cellular homeostasis during trauma/tissue damage through the limitation of local inflammation.

In summary, this study demonstrates a novel mechanism underlying trauma-induced mtDNA damage and subsequent self-regulation of cell death and inflammation aiming to maintain cellular homeostasis. Targeting the signaling revealed in this study might serve as a potential approach of therapeutic intervention for the treatment of post-trauma inflammation. 


\section{Materials and Methods}

Animal strains. C57BL/6 wild-type (WT) mice, gp91 ${ }^{\text {phox }}$ knockout (gp91 ${ }^{\text {phox }-1-}$ ) mice, and LC3 knockout $\left(\mathrm{LC}^{-l-}\right)$ mice were purchased from The Jackson Laboratory (Bar Harbor, ME, USA). TLR2 knockout $\left(\mathrm{TLR}^{-1-}{ }^{-}\right.$) mice, TLR4 knockout $\left(\mathrm{TLR}^{-1-}{ }^{-}\right.$) mice, TLR9 knockout (TLR9 ${ }^{-1}$ ) mice, and myeloid differentiation primary response gene 88 knockout (MyD88 ${ }^{-1}$ ) mice were obtained from Dr Billiar's laboratory at the University of Pittsburgh. All animal experimental protocols were reviewed and approved by the Institutional Animal Care and Use Committees of University of Pittsburgh and VA Pittsburgh Healthcare System.

Reagents. Primary antibodies for cell staining were: EEA1 (endosomal marker) antibody (2411S, Cell Signaling Technology, Danvers, MA, USA), LC3 antibody (4599S, Cell Signaling Technology), RIPK1 antibody (610458, BD Biosciences, San Jose, CA, USA), RIPK3 antibody (sc-135170, Santa Cruz Biotechnology, Dallas, TX USA), MitoTracker and LysoTracker (M7514 and L7528, Thermo Fisher Scientific, Pittsburgh, PA, USA), p62/SQSTM1 Antibody (MAB8028, R\&D Systems, Minneapolis, MN, USA). Secondary antibodies including Alexa Fluor 488conjugated anti-mouse lgG, Cy5-conjugated anti-mouse lgG, Alexa Fluor 488conjugated anti-rabbit lgG, and Cy3-conjugated anti-rabbit Ig $G$ were provided by the Center for Biologic Imaging, University of Pittsburgh Medicine Center.

Primary antibodies used for western blotting include CIRP antibody (from Dr Ping Wang, the Feinstein Institute for Medical Research), ${ }^{17}$ HMGB1 antibody (ab18256, Abcam, Cambridge, MA, USA), anti-RIPK1 antibody (610458, BD Biosciences), antiphosphoserine antibody (61-8100, Thermo Fisher Scientific), p47 ${ }^{\text {phox }}$ antibody (sc-14015, Santa Cruz Biotechnology), gp $91^{\text {phox }}$ antibody (sc-5827, Santa Cruz Biotechnology), Endonuclease G antibody (\#4969, Cell Signaling Technology), LC3 antibody (\#4599, Cell Signaling Technology), p62/SQSTM1 antibody (MAB8028, R\&D Systems), GAPDH (D16H11) XP Rabbit mAb (\#5174 Cell Signaling Technology).

In Situ Cell Death Detection Kit, TMR red (TUNEL) was from Roche (12156792910, Indianapolis, IN, USA). Annexin V detection kit was from BD Biosciences. MitoTracker Green FM was from Thermo Fisher Scientific; Dynabeads Protein G Immunoprecipitation Kit (10007D) for immunoprecipitation was from Thermo Fisher Scientific. Transfect reagents, Lipofectamine LTX Reagent with PLUS Reagent (15338100) was purchased from Thermo Fisher Scientific; siNC and siEndoG was purchased from Integrated DNA Technologies (Coralville, IA, USA); Necroptosis inhibitor Necrostatin-1 (BML-AP309-0020) was purchased from Enzo Life Sciences (Farmingdale, NY, USA). Recombinant HMGB1 (1690-HMB-050) was from R\&D Systems. Rabbit IgG isotype control (ab171870) was purchased from Abcam. Recombinant mouse CIRP protein and anti-CIRP antibody were from Dr Ping Wang, the Feinstein Institute for Medical Research. ${ }^{17}$ The recombinant mouse CIRP protein was detected a residual $\sim 10 \mathrm{pg}$ of LPS per $\mu \mathrm{g}$ of CIRP by the Limulus amebocyte lysate assay. ${ }^{17}$ And the anti-CIRP Ab was raised in New Zealand white rabbits by standard procedures at Covance (Princeton, NJ, USA). ${ }^{17}$

Mouse PF model. The mouse PF model was carried out as previously described. ${ }^{28,57}$ Briefly, femurs and tibias were collected from a killed donor mice and then crushed using a sterile mortar and pestle. An amount of $0.5 \mathrm{~g}$ of the bone crush material was homogenized in $2 \mathrm{ml}$ sterile phosphate-buffered solution (PBS) to prepare the BCM. The recipient mouse was anesthetized with ketamine $(50 \mathrm{mg} /$ $\mathrm{kg}$ B.W.) combined with xylazine (5 mg/kg B.W.) and the thighs were squeezed with a hemostat for $30 \mathrm{~s}$ to induce a soft tissue lesion, followed by injection of $0.15 \mathrm{ml}$ of the BCM in the tissue lesion area. Sham animals underwent the same anesthesia procedure and injection of $0.15 \mathrm{ml}$ of normal saline at the thighs.

BMDM isolation and culture. Bone marrow was flushed with prechilled Dulbecco's Modified Eagle Medium (DMEM) from femurs and tibias, which were harvested from WT or gene knockout mice following the previously described method. ${ }^{58}$ Briefly, cell pellets were collected by centrifugation at $4{ }^{\circ} \mathrm{C}$, and erythrocytes were lysed with RBC lysis buffer (eBioscience, San Diego, CA, USA). The resultant cells were then washed two times with PBS and suspended in BMDM culture medium (DMEM containing 10\% FBS complemented with $50 \mu \mathrm{g} / \mathrm{m}$ penicillin/streptomycin and $10 \mathrm{ng} / \mathrm{ml}$ recombinant macrophage-colony stimulating factor (M-CSF; Sigma-Aldrich, St Louis, MO, USA)) at a concentration of $10^{6}$ cells per $\mathrm{ml}$ and seeded into 6-cm ultra-low attachment surface plates (Corning Costar, Corning, NY, USA). The BMDM culture medium was changed on day 3 and day 5. BMDM were fully differentiated and ready for use at day 7 .
Cell staining. BMDM were seeded in a glass-bottomed Petri dish (P35G-0-10C, MatTek Corporation, Ashland, MA, USA) and fixed with $4 \%$ paraformaldehyde for $15 \mathrm{~min}$ at room temperature. After washing with PBS, cells were permeabilized with $0.01 \%$ Triton X-100 in PBS for 15 min at room temperature, followed by blocking with $5 \%$ bovine serum albumin in PBS for $1 \mathrm{~h}$ at room temperature. The cells were stained with TUNEL following manufacturer's instructions or were incubated with a primary antibody at $4{ }^{\circ} \mathrm{C}$ overnight, followed by incubation with fluorescenceconjugated secondary antibody for $1 \mathrm{~h}$ at room temperature. Cell nucleus was stained with Hoechst 33258 (Sigma-Aldrich). The BMDM were then measured by confocal microscopy (Olympus, Fluoview-FV1000, Olympus America Co., Center Valley, PA, USA). Cells were counted in three random fields in each independent experiment. We then quantified the colocalization of the target proteins by Pearson's coefficient using ImageJ version 1.50i.

Western blot. BMDM lysates were separated by 8 and $15 \%$ SDS-PAGE, and then transferred onto PVDF membranes. After blocking for $1 \mathrm{~h}$ at room temperature with blocking buffer (LI-COR Biosciences, Lincoln, NE, USA), blots were incubated with primary antibody at $4{ }^{\circ} \mathrm{C}$ overnight, followed by incubation with appropriate secondary antibodies (LI-COR Biosciences) for $1 \mathrm{~h}$. Protein bands were detected using the Odyssey System from LI-COR Biosciences and the intensity of each band was quantified using ImageJ version 1.50i. The intensity of target protein band was normalized with reference protein band and calculated for the fold changing.

DNA extraction, mtDNA quantitative and damage rate calculation. Total DNA was isolated from BMDM using DNAzol DNA Isolation Reagents (Thermo Fisher Scientific) by following the instructions. Real-time PCR was done using the iTaq Universal SYBR Green Supermix (1725121, Bio-Rad, Hercules, CA, USA) in a Bio-Rad iQ5 real-time PCR machine (Bio-Rad). The following gene-specific primers were used for amplifying genes: Mt-1 forward, 5'- GCCGTACTGCTCCTATT ATCACTA -3', and reverse, 5'-AGAATCAGAACAGATGCTGGTAGA-3'; Mt-2 forward, 5'-TGATGGTACGGACGAACAGA-3', and reverse, 5'-GCCTTCTATT GCTGATGGTAGTC-3'; Mt-3 forward, 5'-GCCCCAGATATAGCATTCCC-3', and reverse, 5'-GTTCATCCTGTTCCTGCTCC-3'; and GAPDH forward, 5'-AACCTGC CAAGTATGATGA-3' and reverse, 5'-GGAGTTGCTGTTGAAGTC-3'. The forward and reverse sequences of $M t-1, M t-2$, and Mt-3 have been checked on NCBI BLAST for bacterial homology. All of these sequences do not match the gene sequences of microbes. The BLAST results show that Mt- 1 and Mt-3 targets mouse mtDNA cytochrome oxidase subunit 1 gene sequences, and Mt-2 targets mouse mtDNA NADH dehydrogenase subunit 5 gene sequences.

Amplification was performed with cycling conditions of $95^{\circ} \mathrm{C}$ for $15 \mathrm{~s}$ then $60^{\circ} \mathrm{C}$ for $30 \mathrm{~s}$ for 40 cycles. After the amplification protocol was completed, PCR product was subjected to melt-curve analysis using Bio-Rad iQ5 software (Bio-Rad). Fold change was calculated using the $\Delta \Delta$ threshold cycle method and the value for the GAPDH gene, which was normalized to untreated groups. mtDNA damage was calculated by the ratio of long and short segments amplified from mtDNA PCR production. The primers used were: long segments primers- $m t$ long forward, $5^{\prime}$-GCCAGCCTGACC CATAGCCATAATAT-3', and reverse, 5'-GAGAGATTTTATGGGTGTAATGCGG-3'; short segments primers-mt short forward, 5'-CCCAGCTACTACCATCATTCAA GT-3', and reverse, 5'-GATGGTTTGGGAGATTGGTTGATGT-3'; Reference segments primers: $\beta$-Globin forward, 5'-TTGAGACTGTGATTGGCAATGCCT-3', and reverse, $5^{\prime}$-CCTTTAATGCCCATCCCGGACT- $3^{\prime}{ }^{59} \mathrm{PCR}$ was done using the TaKaRa Ex Taq DNA polymerase (Clontech Laboratories, Inc., Mountain View, CA, USA) in Applied Biosystems PCR machine (Thermo Fisher Scientific). Amplification was performed with cycling conditions of $94^{\circ} \mathrm{C}$ for $30 \mathrm{~s}$ then $55^{\circ} \mathrm{C}$ for $60 \mathrm{~s}$ and $72{ }^{\circ} \mathrm{C}$ for $10 \mathrm{~min}$ for 30 cycles. PCR product was quantified by using of NanoDrop spectrophotometer (NanoDrop, Wilmington, DE, USA). The mtDNA long and short PCR production normalized to $\beta$-Globin, respectively, and calculated the mtDNA damage rate $(\%)$ using the following formula:

mtDNA damage rate $(\%)=[($ mtDNA short segment fold induction

-mtDNA long fragment fold induction)/mtDNA short segment fold induction] $\times 100 \%$

RNA extraction and quantitative real-time PCR. The cells form co-culture bottom wells BMDM were harvested and total RNA was isolated by using TRIzol RNA Isolation Reagents (Thermo Fisher Scientific) by following the instructions. Real-time RT-PCR was done using iTaq Universal SYBR Green Supermix (1725121, Bio-Rad) in a Bio-Rad iQ5 real-time PCR machine (Bio-Rad). The following gene-specific primers were used for amplifying genes: $p 62$ forward, 5'-AGGATGGGGACTTGGTTGC-3', and reverse, 5'-TCACAGATCACATTGGGGT 
GC-3'; Endonuclease G forward, 5'-GGAAGTCCTATGTGAAGTA-3', and reverse, 5'-ATCAGCACCTTGAAGAAG-3'; IL-1 $\beta$ forward, 5'-GAAATGCCACCTTTTGAC ATG-3', and reverse, 5'-TGGATGCTCTCATCAGGACAG-3'; IL-6 forward, 5'-CCAA GAGGTGAGTGAGTGCTTCCC-3', and reverse, 5'-CTGTTGTTCAGACTCTC TCCCT-3'; IL-12 forward, 5'-AAGTGGAAGACATTAAGGAAGAA-3', and reverse, 5'-CCAACCAAGCAGAAGACA-3'; TNF- $\alpha$ forward, 5'-GACGTGGAACTGGCAGAA GAG-3', and reverse, 5'-TTGGTGGTTTGTGAGTGTGAG-3'; NOS2 forward, 5'-CC GCCGCTCTAATACTTA-3', and reverse, 5'-TTCATCAAGGAATTATACAGGAA-3'; and $18 S$ forward, 5'-GTAACCCGTTGAACCCCATT-3' and reverse, 5'-CCATCCA ATCGGTAGTAGCG-3'. Reverse transcription was done using iScript Reverse Transcription Supermix (170-8840, Bio-Rad) following the manufacturer's instructions. Amplification was performed with cycling conditions of $95{ }^{\circ} \mathrm{C}$ for $15 \mathrm{~s}$ then $60^{\circ} \mathrm{C}$ for $30 \mathrm{~s}$ for 40 cycles. After the amplification protocol was completed, PCR product was subjected to melt-curve analysis using Bio-Rad iQ5 software (Bio-Rad). Fold change was calculated using the $\Delta \Delta$ threshold cycle method ${ }^{60}$ and the value for the $18 \mathrm{~S}$ gene, which was normalized to untreated groups.

Immunoprecipitation and detection of phosphorylated $\mathrm{p} 47^{\text {phox }}$ and $\mathrm{p} 47^{\text {phox }}$ - gp91 $1^{\text {phox }}$ association. BMDM were lysed in cell lysis buffer (9803, Cell Signaling Technology, Danvers, MA, USA) with protease inhibitor cocktails and PMSF (P8340 and 93482, Sigma-Aldrich). The lysed cell protein was immunoprecipitated with anti-p47 $7^{\text {phox }}$ antibody (sc-14015, Santa Cruz Biotechnology) using Dynabeads protein G immunoprecipitation kit (10007D, Thermo Fisher Scientific). The immunoprecipitated proteins were then subjected to immunoblotting analysis using anti-phosphoserine antibody (61-8100, Thermo Fisher Scientific) and anti-gp91 $1^{\text {phox }}$ antibody (sc-5827, Santa Cruz Biotechnology), respectively.

Data presentation and statistical analysis. The data are presented as mean \pm S.E.M. of the indicated number of experiments. SPSS 19.0 was used for statistical analysis. Significances between groups were determined by using independent samples two-tailed Student's $t$-test. $P<0.05$ was considered as statistically significant.

\section{Conflict of Interest}

The authors declare no conflict of interest.

Acknowledgements. This work was supported by the National Institutes of Health Grant R01-HL-079669 (JF and MAW), National Institutes of Health Grant R56HL-123882 (JF), National Institutes of Health Grant R01HL076179-09 (PW and JF), VA Merit Award 1101BX002729 (JF), National Natural Science Foundation of China 81470262 (JF), Grant of NSFC-Guangdong Joint Foundation of China (No. U1601225 to JY), Guangdong Provincial Key Laboratory Construction Project of China (No. 2014B030301044 to JY), Key Scientific and Technological Program of Guangzhou City (No. 201607020016 to JY), and National Institutes of Health Grant R01GM102146 (MJS).

\section{Author contributions}

ZL, YL, EF and JL planned and did experiments including cell isolation and treatment, confocal microcopy, western blotting, and flow cytometry; ZL, YL and JL did animal experiments; TRB, MAW, SL, WX, YJ, PW and JF planned the project and conceived the experiments; ZL, EF, MJS, PW and JF conceived the data and wrote the manuscript.

1. Haagsma JA, Graetz N, Bolliger I, Naghavi M, Higashi H, Mullany EC et al. The global burden of injury: incidence, mortality, disability-adjusted life years and time trends from the Global Burden of Disease study 2013. Inj Prev 2016; 22: 3-18.

2. Kauvar DS, Lefering R, Wade CE. Impact of hemorrhage on trauma outcome: an overview of epidemiology, clinical presentations, and therapeutic considerations. J Trauma 2006; 60(6 Suppl): S3-11.

3. Heckbert SR, Vedder NB, Hoffman W, Winn RK, Hudson LD, Jurkovich GJ et al. Outcome after hemorrhagic shock in trauma patients. J Trauma 1998; 45: 545-549.

4. Sperry JL, Nathens AB, Frankel HL, Vanek SL, Moore EE, Maier RV et al. Characterization of the gender dimorphism after injury and hemorrhagic shock: are hormonal differences responsible? Crit Care Med 2008; 36: 1838-1845.

5. Sperry JL, Friese RS, Frankel HL, West MA, Cuschieri J, Moore EE et al. Male gender is associated with excessive IL-6 expression following severe injury. J Trauma 2008; 64: 572-578, discussion 578-579.
6. Manson J, Thiemermann C, Brohi K. Trauma alarmins as activators of damage-induced inflammation. Br J Surg 2012; 99(Suppl 1): 12-20.

7. Pugin $\mathrm{J}$. How tissue injury alarms the immune system and causes a systemic inflammatory response syndrome. Ann Intensive Care 2012; 2: 27.

8. Li Z, Scott MJ, Fan EK, Li Y, Liu J, Xiao G et al. Tissue damage negatively regulates LPS-induced macrophage necroptosis. Cell Death Differ 2016; 23: 1428-1447.

9. Moriwaki K, Balaji S, McQuade T, Malhotra N, Kang J, Chan FK. The necroptosis adaptor RIPK3 promotes injury-induced cytokine expression and tissue repair. Immunity 2014; 41 567-578.

10. Rickard JA, O'Donnell JA, Evans JM, Lalaoui N, Poh AR, Rogers T et al. RIPK1 regulates RIPK3-MLKL-driven systemic inflammation and emergency hematopoiesis. Cell 2014; 157: $1175-1188$.

11. Bleriot C, Dupuis T, Jouvion G, Eberl G, Disson O, Lecuit M. Liver-resident macrophage necroptosis orchestrates type 1 microbicidal inflammation and type-2-mediated tissue repair during bacterial infection. Immunity 2015; 42: 145-158.

12. Pasparakis $M$, Vandenabeele $P$. Necroptosis and its role in inflammation. Nature 2015; 517 311-320.

13. Nishiyama $\mathrm{H}$, Danno $\mathrm{S}$, Kaneko $\mathrm{Y}$, Itoh $\mathrm{K}$, Yokoi $\mathrm{H}$, Fukumoto $\mathrm{M}$ et al. Decreased expression of cold-inducible RNA-binding protein (CIRP) in male germ cells at elevated temperature. Am J Pathol 1998; 152: 289-296.

14. Nishiyama $\mathrm{H}$, Itoh $\mathrm{K}$, Kaneko $\mathrm{Y}$, Kishishita M, Yoshida O, Fujita J. A glycine-rich RNA-binding protein mediating cold-inducible suppression of mammalian cell growth. J Cell Biol 1997; 137: 899-908.

15. Morf J, Rey G, Schneider K, Stratmann M, Fujita J, Naef F et al. Cold-inducible RNA-binding protein modulates circadian gene expression posttranscriptionally. Science 2012; 338: 379-383.

16. Lord JM, Midwinter MJ, Chen YF, Belli A, Brohi K, Kovacs EJ et al. The systemic immune response to trauma: an overview of pathophysiology and treatment. Lancet 2014; 384 $1455-1465$.

17. Qiang X, Yang WL, Wu R, Zhou M, Jacob A, Dong W et al. Cold-inducible RNA-binding protein (CIRP) triggers inflammatory responses in hemorrhagic shock and sepsis. Nat Med 2013; 19: 1489-1495.

18. Yang WL, Sharma A, Wang Z, Li Z, Fan J, Wang P. Cold-inducible RNA-binding protein causes endothelial dysfunction via activation of Nirp3 inflammasome. Sci Rep 2016; 6 : 26571.

19. McBride HM, Neuspiel M, Wasiak S. Mitochondria: more than just a powerhouse. Curr Biol 2006; 16: R551-R560.

20. Shoubridge EA. The ABCs of mitochondrial transcription. Nat Genet 2002; 31: 227-228.

21. Anderson S, Bankier AT, Barrell BG, de Bruijn MH, Coulson AR, Drouin J et al. Sequence and organization of the human mitochondrial genome. Nature 1981; 290: $457-465$.

22. Di Caro V, Walko TD 3rd, Bola RA, Hong JD, Pang D, Hsue V et al. Plasma mitochondria DNA-a novel DAMP in pediatric sepsis. Shock 2016; 45: 506-511.

23. Zhang $Q$, Raoof $M$, Chen $Y$, Sumi $Y$, Sursal $T$, Junger $W$ et al. Circulating mitochondrial DAMPs cause inflammatory responses to injury. Nature 2010; 464: 104-107.

24. Galluzzi L, Joza N, Tasdemir E, Maiuri MC, Hengartner M, Abrams JM et al. No death without life: vital functions of apoptotic effectors. Cell Death Differ 2008; 15: 1113-1123.

25. Huang KJ, Ku CC, Lehman IR. Endonuclease G: a role for the enzyme in recombination and cellular proliferation. Proc Natl Acad Sci USA 2006; 103: 8995-9000.

26. $L i$ LY, Luo $X$, Wang $X$. Endonuclease $G$ is an apoptotic DNase when released from mitochondria. Nature 2001; 412: 95-99.

27. Zhou Q, Li H, Li H, Nakagawa A, Lin JL, Lee ES et al. Mitochondrial endonuclease G mediates breakdown of paternal mitochondria upon fertilization. Science 2016; 353 394-399.

28. Darwiche SS, Kobbe P, Pfeifer R, Kohut L, Pape HC, Billiar T. Pseudofracture: an acute peripheral tissue trauma model. J Vis Exp 2011; 50.

29. Mellman I. Endocytosis and molecular sorting. Annu Rev Cell Dev Biol 1996; 12: 575-625.

30. Hashiguchi K, Zhang-Akiyama QM. Establishment of human cell lines lacking mitochondrial DNA. Methods Mol Biol 2009; 554: 383-391.

31. Nakahira K, Haspel JA, Rathinam VA, Lee SJ, Dolinay T, Lam HC et al. Autophagy proteins regulate innate immune responses by inhibiting the release of mitochondrial DNA mediated by the NALP3 inflammasome. Nat Immunol 2011; 12: 222-230.

32. Kukat A, Kukat C, Brocher J, Schafer I, Krohne G, Trounce IA et al. Generation of rhoO cells utilizing a mitochondrially targeted restriction endonuclease and comparative analyses. Nucleic Acids Res 2008; 36: e44.

33. Kafasla $\mathrm{P}$, Skliris A, Kontoyiannis DL. Post-transcriptional coordination of immunological responses by RNA-binding proteins. Nat Immunol 2014; 15: 492-502.

34. Leadsham JE, Sanders G, Giannaki S, Bastow EL, Hutton R, Naeimi WR et al. Loss of cytochrome $\mathrm{c}$ oxidase promotes RAS-dependent ROS production from the ER resident NADPH oxidase, Yno1p, in yeast. Cell Metab 2013; 18: 279-286.

35. Shokolenko I, Venediktova N, Bochkareva A, Wilson GL, Alexeyev MF. Oxidative stress induces degradation of mitochondrial DNA. Nucleic Acids Res 2009; 37: 2539-2548.

36. Panday A, Sahoo MK, Osorio D, Batra S. NADPH oxidases: an overview from structure to innate immunity-associated pathologies. Cell Mol Immunol 2015; 12: 5-23.

37. Fan J, L L Y Vodovotz $Y$, Billiar TR, Wilson MA. Neutrophil NAD(P)H oxidase is required for hemorrhagic shock-enhanced TLR2 up-regulation in alveolar macrophages in response to LPS. Shock 2007; 28: 213-218. 
38. Touyz RM, Chen X, Tabet F, Yao G, He G, Quinn MT et al. Expression of a functionally active gp91phox-containing neutrophil-type $\mathrm{NAD}(\mathrm{P}) \mathrm{H}$ oxidase in smooth muscle cells from human resistance arteries: regulation by angiotensin II. Circ Res 2002; 90: 1205-1213.

39. Zhang J, Dong M, Li L, Fan Y, Pathre P, Dong J et al. Endonuclease $\mathrm{G}$ is required for early embryogenesis and normal apoptosis in mice. Proc Natl Acad Sci USA 2003; 100 : 15782-15787.

40. Glick D, Barth S, Macleod KF. Autophagy: cellular and molecular mechanisms. J Pathol 2010; 221: 3-12

41. Ashrafi G, Schwarz TL. The pathways of mitophagy for quality control and clearance of mitochondria. Cell Death Differ 2013; 20: 31-42.

42. Kubli DA, Gustafsson AB. Mitochondria and mitophagy: the yin and yang of cell death control. Circ Res 2012; 111: 1208-1221.

43. Mizushima N, Yoshimori T, Levine B. Methods in mammalian autophagy research. Cell 2010; 140: 313-326.

44. Pankiv S, Clausen TH, Lamark T, Brech A, Bruun JA, Outzen H et al. p62/SQSTM1 binds directly to Atg8/LC3 to facilitate degradation of ubiquitinated protein aggregates by autophagy. J Biol Chem 2007; 282: 24131-24145.

45. Cadwell K. Crosstalk between autophagy and inflammatory signalling pathways: balancing defence and homeostasis. Nat Rev Immunol 2016; 16: 661-675.

46. Li J, McQuade T, Siemer AB, Napetschnig J, Moriwaki K, Hsiao YS et al. The RIP1/RIP3 necrosome forms a functional amyloid signaling complex required for programmed necrosis. Cell 2012; 150: 339-350.

47. Chan FK, Luz NF, Moriwaki K. Programmed necrosis in the cross talk of cell death and inflammation. Annu Rev Immunol 2015; 33: 79-106.

48. Silke J, Rickard JA, Gerlic M. The diverse role of RIP kinases in necroptosis and inflammation. Nat Immunol 2015; 16: 689-697.

49. McCarthy CG, Wenceslau CF, Goulopoulou S, Ogbi S, Baban B, Sullivan JC et al. Circulating mitochondrial DNA and Toll-like receptor 9 are associated with vascular dysfunction in spontaneously hypertensive rats. Cardiovasc Res 2015; 107: 119-130.

50. Garcia-Martinez I, Santoro N, Chen Y, Hoque R, Ouyang X, Caprio S et al. Hepatocyte mitochondrial DNA drives nonalcoholic steatohepatitis by activation of TLR9. J Clin Invest 2016; 126: 859-864.

51. Fan J, Frey RS, Malik AB. TLR4 signaling induces TLR2 expression in endothelial cells via neutrophil NADPH oxidase. J Clin Invest 2003; 112: 1234-1243.

52. Fan J, Li Y, Levy RM, Fan JJ, Hackam DJ, Vodovotz Y et al. Hemorrhagic shock induces $\mathrm{NAD}(\mathrm{P}) \mathrm{H}$ oxidase activation in neutrophils: role of HMGB1-TLR4 signaling. J Immunol 2007; 178: $6573-6580$
53. Higgins GC, Beart PM, Nagley P. Oxidative stress triggers neuronal caspase-independent death: endonuclease $\mathrm{G}$ involvement in programmed cell death-type III. Cell Mol Life Sci 2009; 66: 2773-2787.

54. Lee JS, Seo TW, Yi JH, Shin KS, Yoo SJ. CHIP has a protective role against oxidative stress-induced cell death through specific regulation of endonuclease G. Cell Death Dis 2013; 4: e666.

55. Li J, Zhou J, Li Y, Qin D, Li P. Mitochondrial fission controls DNA fragmentation by regulating endonuclease G. Free Radic Biol Med 2010; 49: 622-631.

56. van Loo G, Schotte P, van Gurp M, Demol H, Hoorelbeke B, Gevaert K et al. Endonuclease $G$ : a mitochondrial protein released in apoptosis and involved in caspase-independent DNA degradation. Cell Death Differ 2001; 8: 1136-1142.

57. Pfeifer R, Kobbe P, Darwiche SS, Billiar TR, Pape HC. Role of hemorrhage in the induction of systemic inflammation and remote organ damage: analysis of combined pseudo-fracture and hemorrhagic shock. J Orthop Res 2011; 29: 270-274.

58. Weischenfeldt J, Porse B. Bone marrow-derived macrophages (BMM): isolation and applications. CSH Protoc 2008; 2008: pdb prot5080.

59. Kim SJ, Cheresh P, Williams D, Cheng Y, Ridge K, Schumacker PT et al. Mitochondriatargeted Ogg1 and aconitase-2 prevent oxidant-induced mitochondrial DNA damage in alveolar epithelial cells. J Biol Chem 2014; 289: 6165-6176.

60. Livak KJ, Schmittgen TD. Analysis of relative gene expression data using real-time quantitative PCR and the 2(-Delta Delta C(T)) Method. Methods 2001; 25: 402-408.

(i) Cell Death and Disease is an open-access journal published by Nature Publishing Group. This work is licensed under a Creative Commons Attribution 4.0 International License. The images or other third party material in this article are included in the article's Creative Commons license, unless indicated otherwise in the credit line; if the material is not included under the Creative Commons license, users will need to obtain permission from the license holder to reproduce the material. To view a copy of this license, visit http://creativecommons.org/licenses/by/4.0/

(C) The Author(s) 2017 